\title{
Optimization of CCUS supply chains in the UK: a strategic role for emissions reduction
}

\author{
Grazia Leonzio*1, David Bogle², Pier Ugo Foscolo ${ }^{1}$, Edwin Zondervan ${ }^{3}$
}

${ }^{1}$ Department of Industrial and Information Engineering and Economics, University of L'Aquila, L'Aquila, 18 via G. Gronchi, 67100, Italy;

${ }^{2}$ Department of Chemical Engineering, Centre for Process Systems Engineering, University College London, London, Torrington Place WC1E 6BT, UK;

${ }^{3}$ Department of Production Engineering, Laboratory of Process Systems Engineering, Universität Bremen, Bremen, Leobener Straße D, 28359, Germany

*Corresponding author: grazia.leonzio@graduate.univaq.it

\begin{abstract}
The UK is the second largest emitter of carbon dioxide in Europe. It aims to take urgent actions to achieve the 2030 target for $\mathrm{CO} 2$ emissions reduction imposed by EU environmental policies. Three different carbon capture utilization and storage (CCUS) supply chains are developed giving economic indicators for $\mathrm{CO}_{2}$ utilization routes not implying carbon dioxide hydrogenation (i.e. with high TRL). The study presents an innovative proposal to reduce $\mathrm{CO} 2$ impact in the $\mathrm{UK}$, a country rich in coal, which requires reduction of carbon dioxide emissions from flue gases as the easiest and best performing solution. Bunter Sandstone, Scottish offshore and Ormskirk Sandstone are the storage sites considered, while several attractive potential utilization options are considered. Through minimization of total costs, the CCUS supply chain with Bunter Sandstone as storage site results in the most economically profitable solution due to the highest value of net present value ( $€ 0.554$ trillion) and lowest value of pay back period (2.85 years). Only carbon tax is considered. The total cost is $€ 1.04$ billion€/year. Across the supply chain, $6.4 \mathrm{Mton} / \mathrm{year}$ of carbon dioxide emissions are avoided, to be either stored or used for calcium carbonate production. Future work should consider uncertainty, dynamics of market demand and social aspects.
\end{abstract}

Key works: CCUS supply chain, $\mathrm{CO}_{2}$ reduction, mathematical modeling, optimization. 


\section{Graphical abstract}

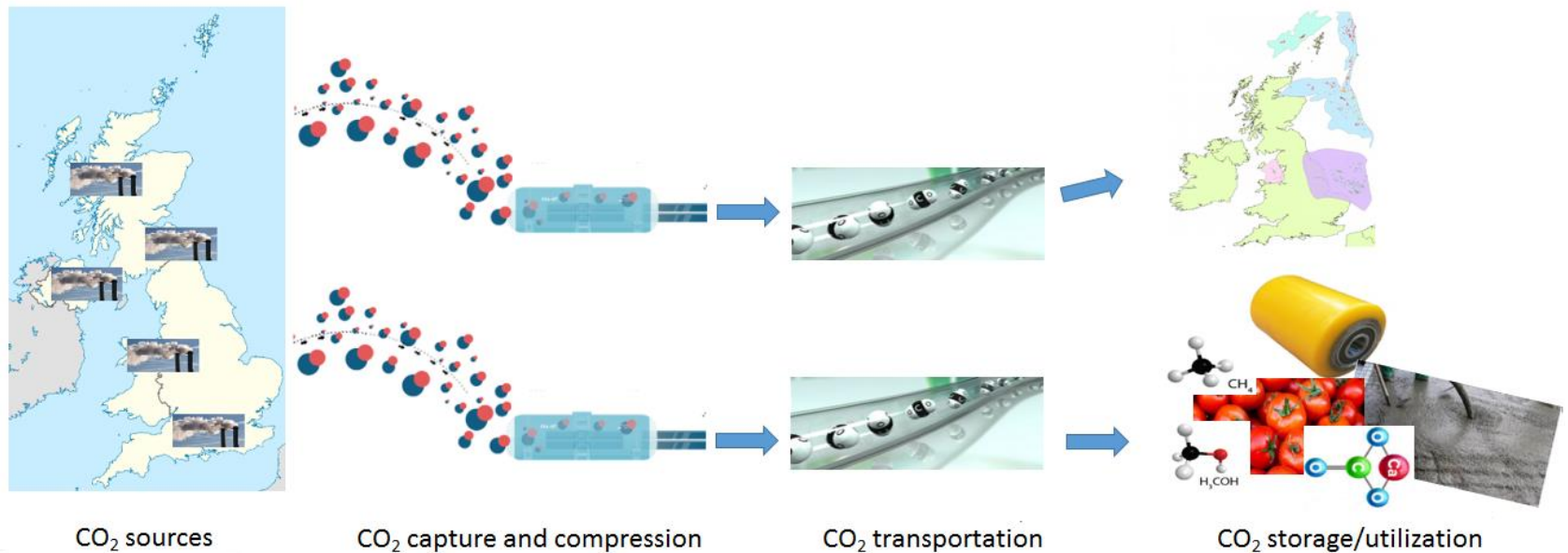




\section{Introduction}

In recent years, energy consumption has increased due to economic development and population growth. Global energy consumption has doubled from 6642.3 million tons oil equivalent (Mtoe) in 1980 to 13105.0 Mtoe in 2015 (Dong et al., 2019). As a consequence, carbon dioxide emissions have increased: in 2018 the average carbon dioxide concentration in the atmosphere was 407 ppm (Meunier et al., 2020), with an increase of 2 ppm/year in the last ten years (IEA, 2016) and 3 ppm/year since 2015 (Dlugokencky, 2018). Global carbon dioxide emissions reached 33.1 Gt in 2018 (IEA, 2019). Public concern has increased and the problem is receiving significant attention from the scientific community. Many efforts are being made to achieve the objectives established in the Paris Agreement limiting global warming to below $2{ }^{\circ} \mathrm{C}$ by setting a target for net zero global emissions in the second half of this century (Yi et al., 2018). This means that global carbon dioxide emissions must be reduced to $24 \mathrm{GtCO}_{2} /$ year by $2030,14 \mathrm{GtCO}_{2} /$ year by 2040 , and $5 \mathrm{GtCO}_{2} /$ year by 2050 (Rogelj et al., 2016). In this context, the European Union (EU) suggests that every EU country should have carbon dioxide emission reductions of $40 \%$ by $2030,60 \%$ by 2040 and $80 \%$ by 2050 in comparison to the 1990 baseline (European Commission, 2011). Such reductions are challenging for all countries.

Carbon capture utilization and storage (CCUS) can account for $7 \%$ of the cumulative carbon dioxide emission reduction capacity required globally by 2040. This would imply a rapid scale-up of CCUS deployment from around 30 million tons of carbon dioxide currently captured each year to $2300 \mathrm{Mt}$ per year by 2040 (Fan et al., 2019). Studies show that without CCUS supply chains it is possible to reduce carbon dioxide emissions within the target with costs raised by about $138 \%$ (IPCC, 2014). CCUS supply chains have the lowest cost for decarbonization operations compared to alternatives. However, for a full development of this system, it is necessary to improve the maturity of the technologies involved as they still have high energy penalties and high costs, to establish more stringent rules and regulations, to limit the risks associated with geological storage and to contribute to an increase in public awareness. Financial support for CCUS systems will also be necessary due to the high costs (Saito et al., 2019; Durmaz et al., 2018; Li et al., 2011; Budinis et al., 2018). CCUS supply chains could and should play a central role in the transition to a low carbon economy.

Many studies involving CCUS supply chains involve carbon dioxide enhanced oil recovery $\left(\mathrm{CO}_{2}\right.$-EOR) where the injected carbon dioxide will remain stored securely (Kuuskraa et al., 2013). The potential application of these technologies in Europe is recognized by Cavanagh and Ringrose (2014). Hasan et al. (2014) designed a CCUS supply chain with $\mathrm{CO}_{2}$-EOR for the United States and find that it is possible to reduce $50 \%-80 \%$ of carbon dioxide emissions with an annual cost of between \$58.1-106.6 billion, generating \$3.4-3.6 billion revenue per year. A multi-scale framework for the optimal design of a CCUS supply chain with oil recovery in the United States was developed by Hasan et al. (2015). A simultaneous selection of capture technologies and materials, carbon dioxide sources, utilization and sequestration sites is considered. At the optimal conditions, the system is able to reduce $50 \%$ of the carbon dioxide emissions at a cost of $\$ 35.63$ per ton of the carbon dioxide captured. Four business models with different stakeholders involved in carbon supply chains are presented by Yao et al. (2018). Different derivative-free optimization methods are used by Rahmawati et 
al. (2015) to maximize the net present value (NPV) of a CCUS supply chain with oil recovery with $\mathrm{CO}_{2}$ utilization and to compare the results with other injection strategies. The NPV is also optimized for these systems by Jahangiri and Zhang (2011) and by Kwak and Kim (2017) who consider fluctuating values of oil and carbon price.

A model for a CCUS supply chain with $\mathrm{CO}_{2}$-EOR was developed by Tapia et al. (2016) considering both stationary and variable carbon dioxide flow rate. Uncertainties in oil price, reservoir oil capacities and oil yield are considered through a Monte Carlo simulation. In a subsequent paper, Tapia et al. (2016b) developed a mixed integer linear programming (MILP) for this system and focus on three important issues: scheduling CCUS operations, allocation of carbon dioxide supply for $\mathrm{CO}_{2}$-EOR operations and matching between carbon dioxide sources and geological storages, as suggested by Sun and Chen (2017). Generally, most of these supply chains are characterized by a source-sink matching method allowing carbon dioxide transportation from a source to the nearest storage location through a pipeline. A more complex connection between the components of a CCUS supply chain, allowing for merging and splitting streams in transportation, is considered by Zhang et al. (2018) for north eastern China. The system is able to reduce $50 \%$ of stationary emissions with an annual cost of $\$ 2.3$ billion and $\$ 0.77$ billion of revenues. A similar case study for China was also developed by Sun et al. (2018). The important role of CCUS supply chains for China is recognized by Yu et al. (2019): they help facilitate energy transactions, support low carbon development and reduce costs of meeting environmental goals. However, Fan et al. (2019) report that economic incentives are required for China so that these systems do not remain in the 'technology valley of death' (Von Stechow et al., 2011).

An economic evaluation of CCUS supply chains with $\mathrm{CO}_{2}$-EOR in Poland was carried out by Mathisen and Skagestad (2017) considering a sensitivity analysis for the price of oil and of carbon dioxide. In Middleton et al. (2015) a CCUS supply chain was developed for the US Gulf Coast region and in nearby regions (Texas, Louisiana, Mississipi, New Mexico, Oklahoma and Kansas) reducing 50 Mton of emissions and producing 200 million bbl/yr of oil, while in Klokk et al. (2010) a $\mathrm{CO}_{2}$-EOR supply chain is optimized for the Norwegian regions.

In addition to oil and gas recovery, carbon dioxide is used to produce other products inside the CCUS supply chain. Carbon dioxide can be used for methane recovery in enhanced coal bed methane production with carbon dioxide injection $\left(\mathrm{CO}_{2}\right.$-ECBM). Huang et al. (2014) analyze a CCUS supply chain with this utilization option through a mixed integer nonlinear programming (MINLP) model. The profit is maximized considering uncertainties in natural gas price and carbon credit.

Carbon dioxide fixation by algae for biofuel production is considered by Yue and You (2015). They present a non-convex MINLP model for Texas to optimize the system according to both economic and environmental criteria using a multi-objective optimization approach. $80 \%$ of carbon dioxide emissions are reduced at a price that is lower compared to other mitigation technologies. Ochoa Bique et al. (2018) integrate a carbon dioxide and a hydrogen supply chain in Germany in order to produce methanol in a sustainable way via hydrogenation. Results show that this solution is feasible only when the electricity for the electrolyzer is delivered for free. In 
Leonzio et al. (2019a) a CCUS supply chain is developed for Germany producing methanol via methane dry reforming with three case studies. Results show that hydrogen production from water electrolysis and renewable power sources is the best case due to a lower environmental impact and higher carbon dioxide consumption. However, in this work a higher amount of methanol compared to the national demand is produced if the target of carbon dioxide reduction is achieved. For this reason Leonzio et al. (2019b) consider using carbon dioxide to produce different products such as urea, methanol, concrete, wheat, polyurethane, calcium carbonate, lignin in a CCUS supply chain for which total costs are minimized. A Monte Carlo simulation is carried out to evaluate the uncertainties regarding the selling price and national demand of the chemical compounds produced. The production of methane in the CCUS supply chain for Italy is developed by Leonzio and Zondervan (2019). The CCUS is integrated with power to gas technology and a comparison among different supply chains is carried out. Results show that economic incentives are required by the systems and the best economic conditions are obtained for the system with the Adriatic Sea as storage site. Gounaris et al, 2016, applied network optimization to design CCUS supply chains of different types.

For those countries not rich in coal but that need to reduce carbon dioxide emissions, carbon dioxide can be captured from flue gas obtained by the co-combustion of coal and biomass and used to produce methanol, as proposed for Spain (Lainez-Aguirre et al., 2017). Similar scenarios, considering biomass as a source of carbon dioxide in a supply chain, are also analyzed and discussed by Perez-Fortes et al., (2017), Yue et al. (2014) and Miret et al. (2016). For carbon capture in a biomass combustion process, a net reduction is achieved for carbon dioxide in the atmosphere but it results in a negative balance for overall carbon dioxide accumulation since biomass growth and conversion is a carbon-neutral cycle.

The models considered above are mainly based on the deterministic minimization or maximization of a single objective function and only the work of Yue and You (2015) considered a deterministic multi objective optimization to consider both economic and environmental aspects. In recent years more complex models have been developed for CCUS supply chain design considering uncertainty, market demand dynamics, etc. Lee et al. (2019) develop a two stage stochastic multi-objective optimization problem maximizing the annual profit, minimizing the environmental impact and uncertainties. The model is based on the 2P2SSMOOP algorithm and the system produces polymers and bio-butanol from carbon dioxide in Korea, achieving the target of emissions reduction set for the year 2030. A multi-objective two stage stochastic optimization was carried out by Zhang et al. (2019) for north east China considering carbon tax uncertainty. The trade-off between the economic and risk objectives was obtained under different conditions.

A stochastic simulation for a CCUS supply chain in the Danish North Sea altering the price of oil and carbon dioxide, discount and hydrocarbon tax rates is considered by Suicmez (2019). The author presents a feasibility study of a CCUS supply chain with $\mathrm{CO}_{2}$-EOR in the North Sea Chalk Field which is the oldest and one of the largest oilfields in the Danish sector: 40 Mton of carbon dioxide can be captured and in this condition the system has a net present value (NPV) value of \$124 million. Uncertainties in the model (in particular in coal 
and carbon trading price) are also considered in the CCUS supply chain developed by Fan et al. (2019) for China.

A model for the integration of carbon and hydrogen supply chains in the UK, producing methanol by carbon dioxide hydrogenation, was developed by Quarton and Samsatli (2020). The model is called Value Web Model for which the objective function is provided by the minimization of a weighted sum of all of the "impacts" of the value chain.

The UK is the country with the second largest carbon dioxide emissions in Europe. In 2014 the UK registered 419.820 Mton of carbon dioxide emission; in Germany it was 719.883 Mton while in Italy 320.411 Mton of carbon dioxide emissions (data.worldbank.org). The UK Climate Change Act states that CCUS supply chains are vital to meet the future target for carbon dioxide emissions reduction. The U.K. government has begun to analyze the costs of these technologies and consider deployment but no concrete actions have been undertaken yet. Carbon supply chains are also important because they have a positive effect on job creation, local economies and productivity.

This study aims to determine CCUS supply chains in the U.K. with minimum cost. Three different CCUS supply chains are considered with different storage sites (Bunter Sandstone in the southern North Sea, Scottish Offshore in the central North Sea and Ormskirk Sandstone in the Irish East Sea). These systems are considered with utilization options all of which are systems with relatively high values for the technology readiness level and likely to provide significant carbon dioxide reduction by the year 2030: calcium carbonate, concrete, tomato, polyurethane production. In addition, methanol and methane production are also considered for comparison. Utilization of $\mathrm{CO}_{2}$ to produce methanol and methane is often considered. They differ from the utilization routes previously mentioned since their production requires carbon dioxide hydrogenation using $\mathrm{H}_{2}$ obtained from green processes (electrolysis utilizing power from renewable sources), which is not yet a mature process at industrial scale.

\section{Model development}

\subsection{Problem statement}

Using a mathematical model for the CCUS supply chain, the optimal connections between carbon dioxide sources and utilization/storage sites can be found to determine the optimal amount of captured carbon dioxide to be used or stored. In order to develop the mathematical model the following assumptions were made:

- One to one coupling: In the utilization and storage section only one source node can be connected with one capture node and one capture node can receive from only one source node although it is possible to connect multiple sources to one capture plant (Kalyanarengan Ravi et al., 2017);

- To avoid transportation of flue gas with additional costs, carbon dioxide sources and capture plants are located at the same site. Flue gases are rather dilute in $\mathrm{CO}_{2}$ (less than 20\%) although their utilization in production processes usually requires high $\mathrm{CO}_{2}$ concentration in the feed gas. This is also true for 
the storage option. As a result $\mathrm{CO}_{2}$ capture plants should be located close to each source site to avoid the burden of transporting a gaseous flow rate of around five times the volume. In addition pure $\mathrm{CO}_{2}$ can be conveniently transported in its liquid physical state under appropriate pressure conditions;

- Within the supply chain carbon dioxide is transported via pipeline because it is the most mature infrastructure able to transport high flow rates of carbon dioxide at low cost (Hasan et al., 2015; Kalyanarengan Ravi et al., 2017);

- Carbon dioxide is assumed to produce polyurethane, concrete and calcium carbonate and in tomato growing (products were selected considering the market demand of 2030 and the relatively high technology readiness level of the respective production processes, which have been quite stable over recent years) as well as methanol and methane (Alberici et al., 2017);

- The supply chain is considered to be operating at steady state condition for a period of 25 years. This assumption influences the amount of carbon dioxide that can be stored each year without exceeding the whole capacity of the storage site. The lifetime of a CCUS supply chain is likely to be long in relation to the resources mobilized. This assumption does not affect cost items because they relate to the processing (capture technology, production and storage processes, etc.) which were taken from official figures available in economic and technical literature sources;

- The demand for carbon dioxide based products is considered constant over time and they can be sold at a stable selling price (Hasan et al., 2015; Zhang et al., 2018). The assumption of stationary conditions is widely utilized for this type of modelling for optimization purposes. The supply chain is evaluated at a time averaged state disregarding major fluctuations for the design of production plants and industrial installations to consider system specifications independent of time required for specific scenarios;

- Only one storage site is present inside the CCUS supply chain able to store an amount of carbon dioxide equal to emissions that need to be reduced to achieve the minimum target imposed by the regulator. Also for utilization no more than two production sites are considered for each carbon dioxide product. The production costs are taken from official average values independent of production location and production capacity of each plant site. Such an assumption is a simplification for the model but it does not affect the main aim of this study which is to calculate an appropriate balance between carbon dioxide storage and utilization processes that satisfies environmental requirements while minimizing costs. Different locations for the production sites would mainly affect the transportation cost of carbon dioxide from capture to utilization site (equation 16), due to distances different from those assumed here. However, this cost item influences only slightly total costs in the utilization section of the supply chain;

- Carbon dioxide capture technologies have an efficiency of $90 \%$ and are able to produce carbon dioxide with a purity at least equal to 90\% for the storage section (Hasan et al., 2012a,b; Nguyen and Zondervan, 2018); 
- Distances between nodes inside the supply chain are evaluated according to their latitude and longitude (Kalyanarengan Ravi et al., 2017; Ochoa Bique et al., 2018);

- The economic feasibility is found through the calculation of the net present value (NPV) and pay back (PB) period;

In addition to these assumptions, some inputs are provided to define the mathematical model:

- Carbon dioxide sources are defined: type, location and yearly emissions (Department of Business, Energy and Industrial Strategy, 2018; naei.beis.gov.uk);

- Carbon dioxide capture and compression process are defined: materials and technologies with respective total costs (Hasan et al., 2014; Nguyen and Zondervan, 2018);

- Carbon dioxide transportation data are defined: distances and relative costs (Serpa et al., 2011; www.nhc.noaa.gov);

- For each carbon dioxide based product a conversion factor is taken into account (Patricio et al., 2017; Ancona et al., 2019; von der Assen et al., 2015; www.defra.gov.uk);

- For each utilization site location and production costs are given (Hank et al., 2018; Reichert, 2012; www.holanda.es; www.colacem.com; Zappa, 2014; Sheldon, 2017; assets.publishing.service.gov.uk; www.prea.co.uk; www.basf.com; apsgroup.uk.com; mineralproducts.org; www.hanson.co.uk; www.calcium-carbonate.org.uk);

- For the storage section the location and respective costs are fixed (Bentham, 2006; Kolstera et al., 2018; Babaei et al., 2016; Kirk, 2005; Gammer et al., 2011; Hendriks, 1994);

- National demand for each product and carbon dioxide reduction targets are given (www.reportlinker.com; $\quad$ www.eia.gov; www.ons.gov.uk; $\quad \underline{\text { www.britishgrowers.org; }}$ mineralproducts.org; Bide et al., 2019);

The mathematical model is able to provide the optimal connection between carbon dioxide sources, carbon dioxide utilization and storage sites. Carbon dioxide sources are selected with the respective capture technologies/materials and connected with the utilization and storage section. The optimal amount of captured and transported carbon dioxide is determined in addition to the amount of each product. The objective is to minimize the total costs, which include carbon dioxide capture and compression costs, carbon dioxide transportation costs, carbon dioxide storage costs and production costs of the different products.

\subsection{CCUS supply chain network model}

In this section, sets, parameters, variables and constraints for the model are defined.

\subsubsection{Sets}

Each element inside the CCUS supply chain is identified by an index. Carbon dioxide sources are represented by 'i', carbon dioxide capture and compression technologies are represented by ' $\mathrm{j}$ ', carbon dioxide storage sites and its complementary utilization section as ' $\mathrm{k}$ ', methanol plants are indicated by ' $\mathrm{m}$ ', power to gas plants 
are indicated by ' $\mathrm{g}$ ', polyurethane plants are indicated by ' $\mathrm{p}$ ', tomato production sites are indicated by ' $\mathrm{t}$ ', concrete plants are indicated by 'c', calcium carbonate plants are represented by ' $\mathrm{d}$ '.

$i \in(1 \ldots . . . I)-$ carbon dioxide sources

$\mathrm{j} \in(1, \ldots \ldots . \mathrm{J})$ - carbon dioxide capture systems

$\mathrm{k} \in(1, \ldots \ldots \mathrm{K})$ - carbon dioxide storage sites and complementary utilization section

$\mathrm{m} \in(1, \ldots . . \mathrm{M})-$ methanol production sites

$\mathrm{g} \in(1, \ldots \ldots \mathrm{G})-$ methane production sites

$\mathrm{p} \in(1, \ldots . . \mathrm{P})$ - polyurethane production sites

$\mathrm{t} \in(1, \ldots \ldots . \mathrm{T})$ - tomato production sites

$\mathrm{c} \in(1, \ldots \ldots \mathrm{C})-$ concrete production sites

$\mathrm{d} \in(1, \ldots \ldots \mathrm{D})$ - calcium carbonate production sites

\subsubsection{Parameters}

The following parameters are set:

$\mathrm{CR}^{\mathrm{min}}$ - Minimum target of overall carbon dioxide reduction (ton/year)

$\mathrm{CS}_{\mathrm{i}}-$ Total carbon dioxide emissions from each source i (ton/year)

$\mathrm{F}_{\mathrm{i}}$ - Total feed flue gas flow rate from each source i $(\mathrm{mol} / \mathrm{s})$

$\mathrm{XS}_{\mathrm{i}}-$ Carbon dioxide composition in the flue gas emission from source $\mathrm{i}(\mathrm{mol} \%)$

$\mathrm{XL}_{\mathrm{i}}$ - Lowest composition processing limit for the capture plant $\mathrm{j}$ (mol\%)

$\mathrm{XH}_{\mathrm{i}}-$ Highest composition processing limit for the capture plant $\mathrm{j}(\mathrm{mol} \%)$

$\mathrm{C}_{\mathrm{k}}{ }^{\max }$ - Maximum storage capacity for the storage site $\mathrm{k}$ (ton)

\subsubsection{Variables}

Continuous and binary variables are used to define the model for the CCUS supply chain. To select the storage site and the capture technology/material the following binary variables are introduced: $X_{i, j, k}$ and $Y_{i, j, k}$. Continuous variables are introduced to define the fraction of captured carbon dioxide that is sent to storage $\left(\mathrm{Fr}_{\mathrm{i}, \mathrm{j}, \mathrm{k}}\right)$, to utilization (Utilization ${ }_{\mathrm{i}, \mathrm{j}, \mathrm{k}}$ ), to methanol production ( Methanol $_{\mathrm{i}, \mathrm{j}, \mathrm{m}}$ ), to methane production $\left(\right.$ Methane $_{\mathrm{i}, \mathrm{j}, \mathrm{g}}$ ), to polyurethane production (Polyurethane $\mathrm{i}_{\mathrm{i}, \mathrm{p}}$ ), to tomato growing $\left(\right.$ Tomato $\left._{\mathrm{i}, \mathrm{j}, \mathrm{t}}\right)$, to concrete curing 
$\left(\right.$ Concrete $\left._{\mathrm{i}, \mathrm{j}, \mathrm{c}}\right)$ and to calcium carbonate production (CalciumCarbonate $\mathrm{e}_{\mathrm{i}, \mathrm{j}, \mathrm{d}}$. A value between 0 and 1 is assumed for these variables.

\subsection{Model development}

\subsubsection{Constraints}

The following constraints are introduced. Carbon dioxide cannot be sent to multiple storage sites so the following constraint is used (see Eq. 1):

$$
\sum_{(j, k) \in(J, K)} X_{i, j, k} \leq 1 \quad \forall i \in I
$$

with $\mathrm{X}_{\mathrm{i}, \mathrm{j}, \mathrm{k}}$ the binary variable already defined. In addition, this inequality ensures the one to one coupling between source and capture technology in the storage section. The storage site is characterized by a defined storage capacity that cannot be exceeded, so the following constraint is used (see Eq. 2):

$$
\sum_{(j, k) \in(J, K)} C S_{i} \cdot F R_{i, j, k} \leq \frac{C_{k}^{\max }}{T H} \quad \forall k \in K
$$

where $\mathrm{CS}_{\mathrm{i}}$ is the total carbon dioxide emissions from source ' $\mathrm{i}$ ' in ton/year, $\mathrm{C}_{\mathrm{k}}{ }^{\max }$ is the maximum storage capacity of the storage site ' $\mathrm{k}$ ' in tons, TH is the time horizon of supply chain in year ( 25 years) and $\mathrm{Fr}_{\mathrm{i}, \mathrm{j}, \mathrm{k}}$ is the variable defined above. The defined CCUS supply chain should achieve the minimum target for carbon dioxide reduction, so this constraint is defined as (see Eq. 3):

$$
\sum_{(i, j, k) \in(I, J, K)} C S_{i} \cdot F R_{i, j, k}+C S_{i} \cdot \text { Utilization }_{i, j, k} \geq C R^{\text {min }}
$$

with $\mathrm{CS}_{\mathrm{i}}$ the total carbon dioxide emission from source ' $\mathrm{i}$ ' in ton/year, $\mathrm{Fr}_{\mathrm{i}, \mathrm{j}, \mathrm{k}}$ and Utilization ${ }_{\mathrm{i}, \mathrm{j}, \mathrm{k}}$ variables defined above and $\mathrm{CR}^{\min }$ the minimum target of $\mathrm{CO}_{2}$ reduction. The whole amount of carbon dioxide that is captured and sent to utilization and storage section should be higher than the minimum target for reduction of its release into the atmosphere. For a selected source not all carbon dioxide can be processed by a selected capture technology: at most only $90 \%$ of carbon dioxide can be captured, as defined by the following constraint (see Eq. 4):

$$
\sum_{(j) \in(J)} F R_{i, j, k}+\text { Utilization }_{i, j, k} \leq 0.9 \quad \forall(i, k) \in(I, K)
$$

with $\mathrm{Fr}_{\mathrm{i}, \mathrm{j}, \mathrm{k}}$ and Utilization ${ }_{\mathrm{i}, \mathrm{j}, \mathrm{k}}$ the continuous variables defined above. Not all the technologies considered can be used to capture carbon dioxide from all sources with a product purity of $90 \%$ for carbon dioxide. This depends on the composition of carbon dioxide in the feed, as defined by the following constraint (see Eq. 5):

$$
\sum_{(k) \in(K)}\left(X H_{j}-X S_{i}\right) \cdot\left(X S_{i}-X L_{j}\right) \cdot X_{i, j, k} \geq 0 \quad \forall(i, j) \in(I, J)
$$


where $\mathrm{XS}_{\mathrm{i}}$ is carbon dioxide composition in flue gas emissions from source $\mathrm{i}(\mathrm{mol} \%), \mathrm{XL}_{\mathrm{j}}$, is the lowest limit of processing composition for capture plant $\mathrm{j}(\mathrm{mol} \%), \mathrm{XH}_{\mathrm{j}}$ is the highest limit of processing composition for capture plant $\mathrm{j}(\mathrm{mol} \%), \mathrm{X}_{\mathrm{i}, \mathrm{j}, \mathrm{k}}$ is the variable defined above. This constraint is required for the storage section, while in the utilization section purity higher or lower than $90 \%$ can be required and achieved in the respective site.

The amount of carbon dioxide that is sent to the utilization section is divided among the different utilization options, according to the following material balance constraint (see Eq. 6):

$$
\text { Utilization }_{i, j, k}=\sum_{k} \text { Product }_{k} \cdot n_{\text {sites }} \quad \forall(i, j, k) \in(I, J, K)
$$

where $\mathrm{k}$ is the index identifying each single product and $\mathrm{n}_{\text {sites }}$ is the number of utilization sites. In the utilization and storage section only one capture technology/material can be chosen for the selected carbon dioxide source, as defined in the following constraint (see Eq. 7):

$$
\sum_{(j) \in(J)} Y_{i, j, k} \leq 1 \quad \forall(i, k) \in(I, K)
$$

with $\mathrm{Y}_{\mathrm{i}, \mathrm{j}, \mathrm{k}}$ the binary variable defined before. In order to convert the mathematical model to a linear one, a glover linearization is applied by using these constraints (see Eq. 8-9):

$$
\begin{array}{cc}
0 \leq F R_{i, j, k} \leq 0.9 \cdot X_{i, j, k} & \forall(i, j, k) \in(I, J, K) \\
0 \cdot Y_{i, j, k} \leq \text { Utilization }_{i, j, k} \leq 0.9 \cdot Y_{i, j, k} & \forall(i, j, k) \in(I, J, K)
\end{array}
$$

where $\mathrm{Fr}_{\mathrm{i}, \mathrm{j}, \mathrm{k}}, \mathrm{X}_{\mathrm{i}, \mathrm{j}, \mathrm{k}}$, Utilization $_{\mathrm{i}, \mathrm{j}, \mathrm{k}}$ and $\mathrm{Y}_{\mathrm{i}, \mathrm{j}, \mathrm{k}}$ were already defined, while 0.9 is used because at least $90 \%$ of carbon dioxide is captured from each carbon dioxide source.

\subsubsection{Equations}

In the mathematical model, equations for carbon capture and compression costs, carbon dioxide transportation costs and storage costs are given. Carbon dioxide capture and compression costs (€/year) are determined according to the following relation (see Eq. 10):

$$
C C_{i, j, k}=C D C_{i, j, k}+C I C_{i, j, k}+C O C_{i, j, k} \quad \forall(i, j, k) \in(I, J, K)
$$

where $C D C_{i, j, k}$ are the flue gas dehydration costs in $€ /$ year equal to $9.28 € /$ tonCO $_{2}$ (Kalyanarengan Ravi et al., 2017), $C I C_{i, j, k}$ are the investment costs in $€ /$ year and $C O C_{i, j, k}$ are the operating costs in $€ /$ year. Investment and operating costs expressions were proposed by Hasan et al. (2014) (see Eq. 11-12):

$$
C I C_{i, j, k}=\alpha_{I, j} \cdot Y_{i, j, k}+\left(\beta_{I, j} \cdot x_{c o 2, i} n_{I, j}+\gamma_{I, j}\right) \cdot F_{i, j, k}^{m_{I, j}} \quad \forall(i, j, k) \in(I, J, K)
$$




$$
\operatorname{COC}_{i, j, k}=\alpha_{o, j} \cdot Y_{i, j, k}+\left(\beta_{o, j} \cdot x_{c o 2, i} n_{o, j}+\gamma_{o, j}\right) \cdot F_{i, j, k}^{m_{o, j}} \quad \forall(i, j, k) \in(I, J, K)
$$

where $\alpha_{I, j}, \alpha_{o, j}, \beta_{I, j}, \beta_{o, j}, \gamma_{I, j}, \gamma_{o, j}, n_{I, j}, n_{o, j}, m_{o, j}, m_{I, j}$ are fixed parameters for each process and for each material shown in Zhang et al. (2018) and in the Appendix (table S1), $\mathrm{X}_{\mathrm{CO} 2, \mathrm{i}}$ is carbon dioxide content in the flue gas for the selected carbon dioxide source, $F_{i, j, k}$ is flue gas flow rate in mol/s and $Y_{i, j, k}$ is the binary parameter defined before. However, for ionic liquid absorption modified equations can be used (see Eq. 1314) (Nguyen and Zondervan, 2018; Nguyen et al. 2018):

$$
\begin{array}{ll}
\operatorname{CIC}_{i, j, k}=\left(\alpha_{I, j} \cdot F_{i, j, k}+\beta_{I, j} \cdot Y_{i, j, k}\right) \cdot x_{c o 2, i}+\gamma_{I, j} \cdot F_{i, j, k}^{m_{I, j}} & \forall(i, j, k) \in(I, J, K) \\
\operatorname{COC}_{i, j, k}=\left(\alpha_{o, j} \cdot F_{i, j, k}+\beta_{o} \cdot Y_{i, j, k}\right) \cdot x_{c o 2, i,}+\gamma_{o, j} \cdot F_{i, j, k}^{m_{o, j}} & \forall(i, j, k) \in(I, J, K)
\end{array}
$$

with $\alpha_{I, j}, \alpha_{o, j}, \beta_{I, j}, \beta_{o, j}, \gamma_{I, j}, \gamma_{o, j}, m_{o, j}, m_{I, j}$ fixed parameters (Nguyen and Zondervan, 2018) (see table S1 in the Appendix), $\mathrm{X}_{\mathrm{CO} 2, \mathrm{i},}$ carbon dioxide composition in the flue gas, $\mathrm{F}_{\mathrm{i}, \mathrm{j}, \mathrm{k}}$ flue gas flow rate in $\mathrm{mol} / \mathrm{s}, \mathrm{Y}_{\mathrm{i}, \mathrm{j}, \mathrm{k}}$ the binary variable defined above.

Carbon dioxide is transported within the CCUS supply chain via pipeline and the relation to calculate these costs is reported by Serpa et al. (2011), where the total costs (TC in $€ /$ year) are the sum of investment (TIC in $€ /$ year) and operating costs (TOC in $€ /$ year) (see Eq. 15):

$$
\begin{aligned}
& T C_{i, j, k, c, t, p, d, m, g}=T I C_{i, j, k, c, t, p, d, m, g}+T O C_{i, j, k, c, t, p, d, m, g} \\
& \in(I, J, K, C, T, P, D, M, G)
\end{aligned}
$$

The investment costs are determined from this relation (see Eq. 16) (Serpa et al., 2011):

$$
\begin{aligned}
\operatorname{TIC}_{i, j, k, c, t, p, d, m, g} & \\
& =\operatorname{CCR}\left(\alpha_{t}\right. \\
& \cdot \operatorname{CS}_{i} \cdot F R_{i, j, k} / \text { Concrete }_{i, j, c} \text { Tomato }_{i, j, t} \text { Polyurethane }_{i, j, p} / \text { Calcium carbonate }_{i, j, d} \\
& \left./ \text { Methanol }_{i, j, m} / \text { Methane }_{i, j, g}+\beta_{t} \cdot X_{i, j, k} / X_{i, j, c} / X_{i, j, t} / X_{i, j, p} / X_{i, j, d} / X_{i, j, m} / X_{i, j, g}\right) \cdot F_{T} \\
& \cdot\left(D_{i, k} / D_{i, c} / D_{i, t} / D_{i, p} / D_{i, d} / D_{i, m} / D_{i, g}+16\right) \\
& \in(I, J, K, C, T, P, D, M, G)
\end{aligned}
$$

where $\alpha_{t}$ is 0.019 and $\beta_{t}$ is 0.533 (Serpa et al., 2011), CCR is the capital cost recovery, $D_{i, k} / D_{i, d} / D_{i, t} /$ $D_{i, p} / D_{i, d} / D_{i, m} / D_{i, g}$ are the distance respectively between carbon dioxide sources and storage site, concrete production site, tomato production site, polyurethane production site, calcium carbonate production site, methanol production site, methane production site evaluated according to latitude and longitude (Kalyanarengan Ravi et al., 2017), $\mathrm{F}_{\mathrm{T}}$ is a terrestrial factor of 1.2 (Broek et al., 2010), $16 \mathrm{Km}$ are added to the distance to consider additional paths related to process (Dahowski et al., 2004), $\mathrm{F}_{\mathrm{i}, \mathrm{j}, \mathrm{k}}$, Methanol $\mathrm{i}_{\mathrm{i}, \mathrm{j}, \mathrm{m}}$, Methane $\mathrm{i}_{\mathrm{i}, \mathrm{g}, \mathrm{g}}$, Polyurethane $_{\mathrm{i}, \mathrm{j}, \mathrm{p}}$, Tomato $\mathrm{i}_{\mathrm{i}, \mathrm{j}, \mathrm{t}}$, Concrete $\mathrm{i}_{\mathrm{i}, \mathrm{j}, \mathrm{c}}$ and CalciumCarbonate $\mathrm{e}_{\mathrm{i}, \mathrm{j}, \mathrm{d}}$, are the continuous variables already defined, and $X_{i, j, k}, X_{i, j, c}, X_{i, j, t}, X_{i, j, d}, X_{i, j, m}, X_{i, j, g}$ are 1 if the respective continuous variable is not 0 . The operating costs are $4 \%$ of investment costs (Kalyanarengan Ravi et al., 2017). 
Carbon dioxide storage costs (SC in $€ /$ year) are the sum of investment (SIC in $€ /$ year) and operating costs (SOC in $€ /$ year) (Kalyanarengan Ravi et al., 2017) (see Eq. 17):

$$
S C_{k}=S I C_{k}+S O C_{k}
$$

Investment costs are determined from (Hendriks, 1994) (see Eq. 18):

$$
\operatorname{SIC}_{k}=\operatorname{CCR} \cdot\left(m \cdot d_{\text {well }}+b\right) \cdot N_{\text {well }}^{\text {build }}{ }_{k}
$$

where $\mathrm{m}$ and $\mathrm{b}$ are parameters respectively of $1.53 \mathrm{M} € / \mathrm{km}$ and 1.23 M€ (Hendriks, 1994), $\mathrm{d}_{\text {well }}$ is the depth of the well, CCR is the capital cost recovery and $N_{\text {well }}^{\text {build }}$ is the number of wells which need to be built evaluated according to this relation (Hasan et al., 2014; Kühn et al., 2013) (see Eq. 19):

$$
N_{\text {well }_{k}}^{\text {build }}=\frac{\sum_{(i, j) \in(I, J)} C S_{i} \cdot F R_{i, j, k}}{I C}
$$

as a function of the injection capacity per well, IC, and amount of stored carbon dioxide. Operating costs are $4 \%$ of investment costs (Kalyanarengan Ravi et al., 2017).

Production costs and selling prices of carbon dioxide products are shown in table 1.

\section{Table 1}

Selling price and production cost of different products of CCUS supply chain in the UK

\begin{tabular}{ccc}
\hline Product & Production costs & Selling price \\
\hline Methanol & $608 € /$ ton (Hank et al., 2018) & $705 € /$ ton (www.ons.gov.uk) \\
Methane & $300 € / \mathrm{MWh}$ (Reichert, 2012) & $0.028 € / \mathrm{kWh}$ (ec.europa.eu) \\
Polyurethane & $1349 € /$ ton & $2590 € /$ ton (www.ons.gov.uk) \\
Tomato growing & $0.85 € / \mathrm{kg}$ (www.holanda.es) & $1.45 € / \mathrm{kg}($ www.gov.uk) \\
Concrete & $21.8 € /$ ton (www.colacem.com) & $32.6 € /$ ton (rmsconcrete.co.uk/prices/) \\
Calcium carbonate & $65.2 € /$ ton (Zappa, 2014) & $120 € /$ ton (Zappa, 2014) \\
\hline
\end{tabular}

The conversion factors for the compounds produced are: 1.7 tonCO $_{2} /$ ton methanol (Patricio et al., 2017), 1 moleCO $2 /$ mole methane (Ancona et al., 2019), $0.3 \mathrm{kgCO}_{2} / \mathrm{kg}$ polyurethane (von der Assen et al., 2015), 2.6 ton tomato/ton $\mathrm{CO}_{2}$ (Patricio et al., 2017; www.defra.gov.uk), 0.03 tonCO $\mathrm{C}_{2} /$ ton concrete (Patricio et al., 2017), 0.25 tonCO $\mathrm{C}_{2} /$ ton steel slag (Patricio et al., 2017).

\subsubsection{Objective function}

The objective function for CCUS supply chain is defined as (see Eq. 19):

$$
\begin{aligned}
& \emptyset=\sum_{(i, j, k, c, t, p, d, m, g)} C C_{i, j, k}+T C_{i, j, k, c, t, p, d, m, g}+S C_{k}+C P_{c}+C P_{t}+C P_{p}+C P_{d}+C P_{m} \\
&+C P_{g} \forall(i, j, k, c, t, p, d, m, g) \in(I, J, K, C, T, P, D, M, G)
\end{aligned}
$$


where $C C_{i, j, k}$ are carbon dioxide capture and compression costs, $C T_{i, j, k, c, t, p, d, m, g}$ are carbon dioxide transportation costs, $S C_{k}$ are carbon dioxide storage costs, $C P_{c}$ are concrete production costs, $C P_{t}$ are tomato production costs, $C P_{p}$ are polyurethane production costs, $C P_{d}$ are calcium carbonate production costs, $C P_{m}$ are methanol production costs, $C P_{g}$ are methane production costs. The objective function is the sum of all costs involved within the CCUS supply chain. This objective function is minimized to design the system.

\subsection{Case study}

The EU Member States have agreed to reduce EU emissions by at least $40 \%$ below 1990 levels by 2030. To achieve this aim, the UK should reduce carbon dioxide emissions by 53\% compared to 1990 levels (www.theccc.org.uk). In the UK, total carbon dioxide emissions in 1990 were of 596.3 Mton, so in 2030 they should be below 320 Mton (Department of Business, Energy and Industrial Strategy, 2019). Carbon dioxide emissions are of 357.5 Mton, so to achieve the target for 2030 an additional reduction of $10.5 \%$ is required (Department of Business, Energy and Industrial Strategy, 2018).

For the carbon capture utilization and storage supply chain only carbon dioxide emissions from industrial and commercial sectors are considered. Four regions, represented by their main city, with higher emissions were selected. The regions of interest are: Wales (14.2 Mton/year), Scotland (13.3 Mton/year), the North West (15.5 Mton/year), Yorkshire and the Humber (18 Mton/year). The nodes are located respectively at Cardiff, Edinburgh, Manchester, Leeds.

Total carbon dioxide emissions in the CCUS supply chain for these regions are equal to $61 \mathrm{Mton} / \mathrm{year}$. These should be reduced by $10.5 \%$, as discussed above. The minimum target of emissions reduction to be obtained by the model is $6.4 \mathrm{Mton} / \mathrm{year}$. Carbon dioxide is mainly emitted by power plants (naei.beis.gov.uk) whose flue gases have a carbon dioxide composition in the range of 4-15 mol\% (Zhang et al., 2018), as reported in table 2, which also shows flue gas flow rates.

\section{Table 2}

Characterization of carbon dioxide sources selected for the CCUS supply chain in the UK

\begin{tabular}{clcc}
\hline Region & $\mathbf{C O}_{\mathbf{2}}$ source & $\begin{array}{c}\mathbf{C O}_{2} \text { composition } \\
(\mathbf{m o l} \%)\end{array}$ & $\begin{array}{c}\text { Flue gas } \\
(\mathbf{m o l} / \mathbf{s})\end{array}$ \\
\hline Wales & Power plant & 10 & 102313 \\
Scotland & Power plant & 12 & 79857 \\
North West & Power plant & 14 & 79771 \\
Yorkshire and the Humber & Power plant & 13 & 99763 \\
\hline
\end{tabular}

In the UK, carbon dioxide can be stored in oil and gas fields or in saline aquifers (Department of Energy \& Climate Change, 2010). The first option is the most important storage type for the UK, with low risk, and with potentially enough storage capacity to meet national carbon capture and storage (CCS) deployment requirements and wide regional distribution. The total storage capacity can be considered in the range of 7.4$9.9 \mathrm{GtCO}_{2}$ (Department of Energy \& Climate Change, 2010). Saline aquifer storages have potentially large 
scale distribution around the UK. The total storage capacity in the UK is in the range of 7.1-14.3 $\mathrm{GtCO}_{2}$ (the potential theoretical capacity exceeds those of oil and gas fields) and is present in the Irish Sea, southern North Sea, and northern/central North Sea (Department of Energy \& Climate Change, 2010). Because of their much larger capacity, saline aquifers are selected in this study for the CCUS supply chains. Three different storage sites near to the selected carbon dioxide sources are identified, one for each CCUS supply chain: Bunter Sandstone in the southern North Sea, Scottish Offshore in the Central North Sea and Ormskirk Sandstone in the Irish East Sea. The main characteristics of these storage sites are reported in table 3.

\section{Table 3}

Data about storage sites considered for the CCUS supply chain of the UK

\begin{tabular}{|c|c|c|c|}
\hline Storage location & Southern North Sea & & \\
\hline Storage area & Bunter Sandstone & & Bentham (2006) \\
\hline Storage site & $1 \backslash 44$ & & Bentham (2006) \\
\hline Storage capacity & 10 & MtonCO ${ }_{2}$ & Bentham (2006) \\
\hline Storage depth & 1600 & $\mathrm{~m}$ & Bentham (2006) \\
\hline Injection capacity per well & 2 & MtonCO $\mathrm{CO}_{2} /$ year & Kolstera et al. (2018) \\
\hline Storage location & Central North sea & & \\
\hline Storage area & Scottish offshore & & \\
\hline Storage site & Forties & & Babaei et al. (2016) \\
\hline Storage capacity & 121 & $\mathrm{MtonCO}_{2}$ & Babaei et al. (2016) \\
\hline Storage depth & 2217 & $\mathrm{~m}$ & Babaei et al. (2016) \\
\hline Injection capacity per well & 3 & $\mathrm{MtonCO}_{2} /$ year & Babaei et al. (2016) \\
\hline Storage location & Irish east sea & & \\
\hline Storage area & Ormskirk sandstone & & Kirk (2005) \\
\hline Storage site & 4 & & Kirk (2005) \\
\hline Storage capacity & 11,5 & $\mathrm{MtonCO}_{2}$ & Kirk (2005) \\
\hline Storage depth & 500 & $\mathrm{~m}$ & Kirk (2005) \\
\hline Injection capacity per well & 2 & $\mathrm{MtonCO}_{2} /$ year & Kirk (2005) \\
\hline
\end{tabular}

Carbon dioxide sources and storage sites are reported in figure 1. 


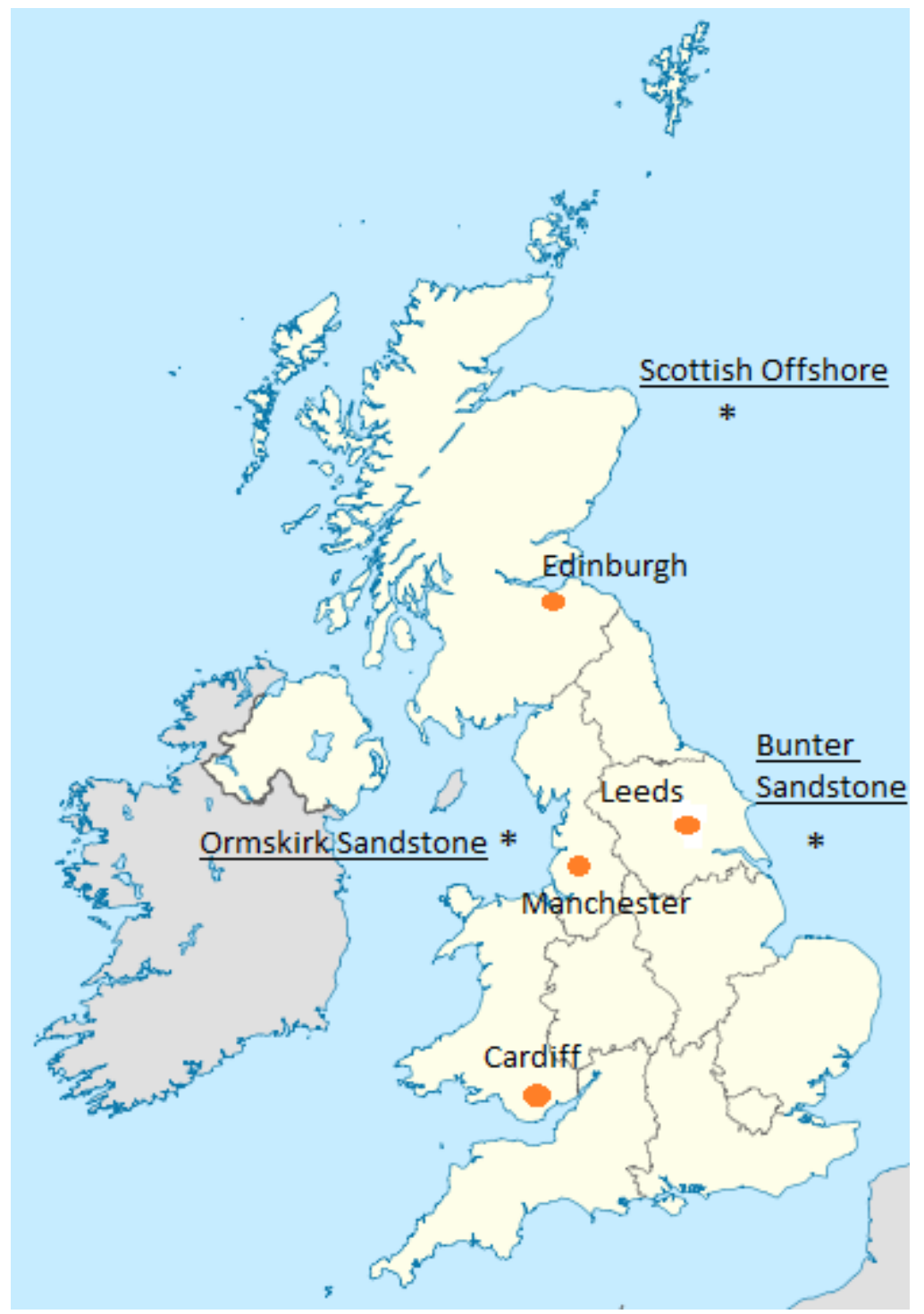

Figure 1 Carbon dioxide sources ( $)$ and storage sites $\left(^{*}\right)$ suggested for the CCUS supply chains of the UK

In the utilization section, carbon dioxide is used to produce calcium carbonate, concrete, tomatoes, polyurethane, methanol and methane. In addition to methanol and methane obtained from $\mathrm{CO}_{2}$ hydrogenation the corresponding carbon dioxide consumed is expected to be considerable according to the projections for the year 2030. The value of UK demand for calcium carbonate, concrete, tomatoes, polyurethane are respectively of 5-43 $\mathrm{KtonCO}_{2} /$ year, 0-100 KtonCO 2 year, 108-2018 $\mathrm{KtonCO}_{2} /$ year, 0-100 $\mathrm{KtonCO}_{2} /$ year (Alberici et al., 2017). Tomatoes are chosen for horticultural production because they have the highest production (www.defra.gov.uk) ahead of cucumbers, peppers and aubergines amongst those suggested as agricultural products that can be obtained from carbon dioxide in the UK (Alberici et al., 2017).

For each carbon dioxide based product different production sites are suggested. For methanol production Billingham is selected (Sheldon, 2017), for methane production Isle of Grain and Avonmouth are selected (assets.publishing.service.gov.uk), for polyurethane production Manchester (www.prea.co.uk) and Alfreton 
(www.basf.com) are suggested, for tomato growing Teesside (apsgroup.uk.com) and the Isle of Wight (apsgroup.uk.com) are considered, for concrete production York (mineralproducts.org) and Wallasey (www.hanson.co.uk) are suggested, while for calcium carbonate production Lifford, Birmingham and Fort William are suggested (www.calcium-carbonate.org.uk). Utilization sites are shown in figure 2.

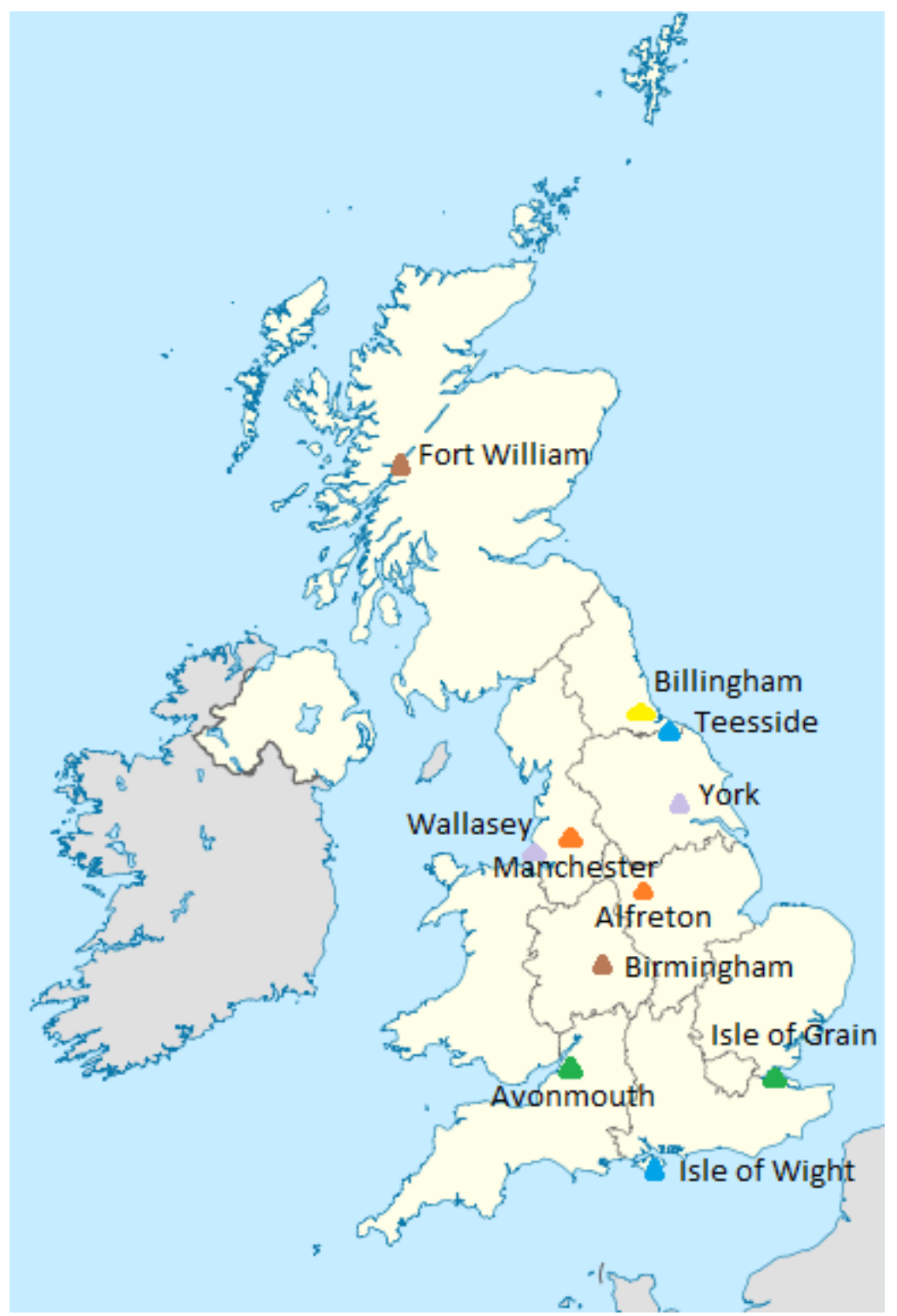

Figure 2 Carbon dioxide utilization sites suggested for the CCUS supply chain in the UK $(\odot$ methanol production site, $\boldsymbol{\Delta}$ methane production site, $\boldsymbol{\Delta}$ polyurethane production site, $\boldsymbol{\Delta}$ tomato production site, concrete production site, $\mathbf{c}$ calcium carbonate production site)

The national demand of each of these products is the following: for methanol $1.64 \cdot 10^{-4}$ Mton/year (www.reportlinker.com), for methane 51.4 Mton/year (www.eia.gov), for polyurethane 0.15 Mton/year (www.ons.gov.uk), for tomato $7.5 \cdot 10^{-2}$ Mton/year (www.britishgrowers.org), for concrete 4.14 Mton/year (mineralproducts.org), for calcium carbonate $6.53 \cdot 10^{-1}$ Mton/year (Bide et al., 2019). 
For carbon dioxide capture different technologies/materials are considered as reported by Leonzio et al. (2019b). For absorption technology, materials such as monoethanolamine (MEA) (30\%wt), piperazine (PZ) (40\% wt) and ionic liquids (IL) (1-butyl-3-methylimidazolium acetate) are proposed. For membrane technology POE1, POE2 and FSCPVAm are considered. For pressure swing adsorption (PSA) and vacuum swing adsorption (VSA) technologies 13X, AHT, MVY and WEI zeolites are considered.

\section{Results and discussion}

In this section, the results for the CCUS supply chains developed for the UK are presented. While the main objective is to reduce carbon dioxide emissions to meet the established target, the systems are designed by minimizing total costs. In each supply chain analyzed 4 carbon dioxide sources, 14 capture technologies/materials, 1 storage site and 11 utilization sites are considered. The models is formulated as a Mixed Integer Linear Programming model developed in AIMMS and using CPLEX 12.7.1 as the selected solver. The model has 6423 (112 integer) variables and 7614 constraints. The computer processor is $2.5 \mathrm{GHz}$ with 4 GB memory.

\subsection{Results of the CCUS supply chain with Bunter Sandstone as storage site}

Table 4 shows the optimal topology of the considered CCUS supply chain, with the amount of carbon dioxide that is sent to utilization or storage from the selected source. The optimal solution was found in 0.58 seconds in 54 iterations.

\section{Table 4}

Topology of the CCUS supply chain in the UK with Bunter Sandstone storage site

\begin{tabular}{ccc}
\hline $\mathbf{C O}_{2}$ source & $\mathbf{C O}_{2}$ capture technology/material & $\begin{array}{c}\mathbf{C O}_{2} \text { amount } \\
(\mathbf{M t o n} / \mathbf{y} \text { ear })\end{array}$ \\
\hline Teeds & To storage & \\
\hline \multicolumn{3}{c}{ MEA absorption } \\
\hline Leeds & To utilization & 0.4 \\
\hline
\end{tabular}

The system considers 61 Mton/year of carbon dioxide (in the four regions taken in the account in this study) and captures 6.4 Mton/year of carbon dioxide. 6 Mton/year of carbon dioxide are sent to the utilization section while $0.4 \mathrm{Mton} / \mathrm{year}$ of carbon dioxide are sent to storage. The minimum target for carbon dioxide reduction is achieved. For both cases, Leeds is the selected source. For the storage section, MEA absorption is the suggested capture technology, while for the utilization section PZ absorption is selected. As found in our previous studies (Leonzio et al., 2019b) absorption technology is the preferred choice due to lower costs than for other technologies. The lower costs of absorption are also reported in Hasan et al. (2012b), comparing absorption, membrane, PSA and VSA technologies at different flue gas flow rate and carbon dioxide composition. Also, it is possible to verify that the selection of capture material depends on the final use of carbon dioxide, in addition to its treated amount (Leonzio et al., 2019b). For a fixed carbon dioxide 
composition, as in this case study, PZ is preferred at higher flow rate due to the lower costs, as shown by Kalyanarengan Ravi et al. (2017). For low flow rate, the costs of MEA and PZ are comparable and MEA absorption capture technology is suggested.

As expected the selected carbon dioxide source is connected to a storage site in the Yorkshire and the Humber region (with Leeds as main city), because it is nearby. This reduces carbon dioxide transportation costs. In the utilization section, carbon dioxide is used to produce calcium carbonate, with an amount of 5.4 Mton/year, higher than the national demand (a fraction of produced calcium carbonate can be exported to other countries). Calcium carbonate is produced at Lifford, Birmingham and at Fort William. The graphical topology of this optimized supply chain is shown in figure 3.

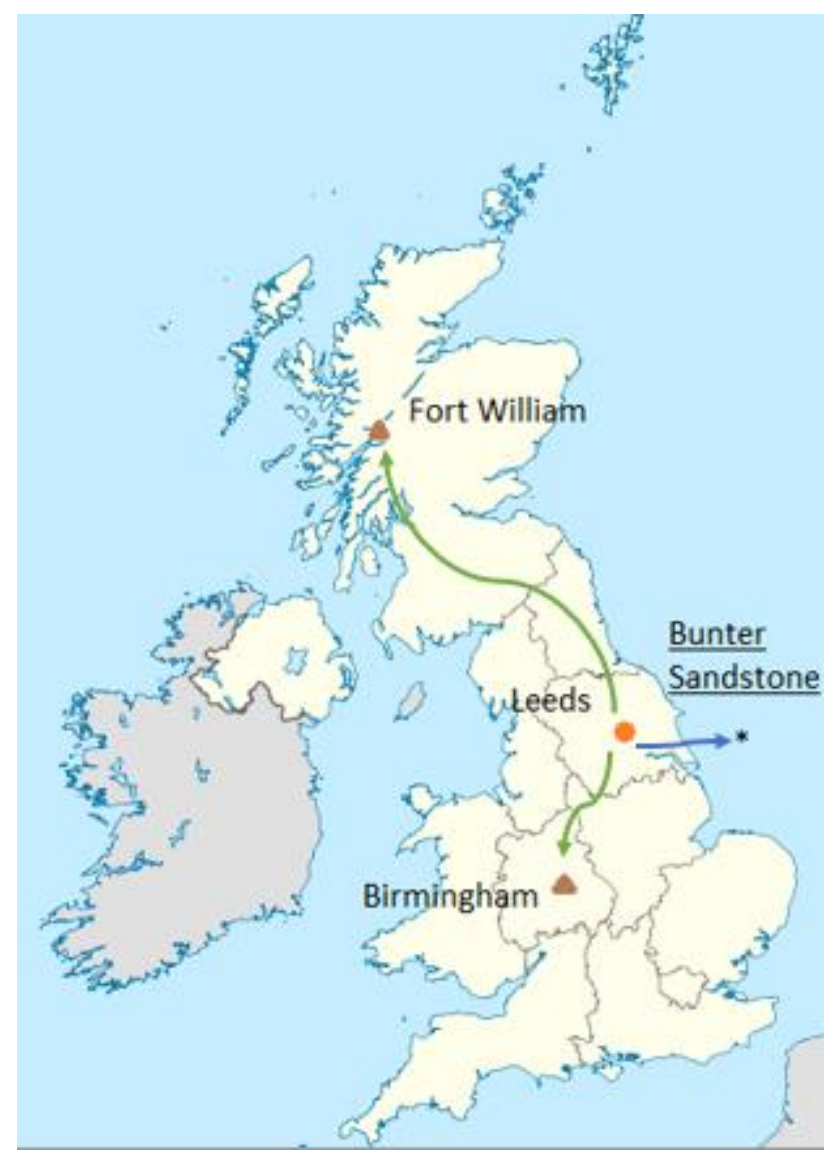

Figure 3 Topology of the optimized CCUS supply chain with Bunter Sandstone as storage site ( $>$ carbon dioxide source, $*$ carbon dioxide storage, $\boldsymbol{v}$ calcium carbonate production site, $\longrightarrow$ to storage site, $\longrightarrow$ to utilization site)

Carbon dioxide capture and compression costs are 0.687 billion $€ /$ year, carbon dioxide transportation costs are 2.16 million $€ /$ year, carbon dioxide storage costs are 0.765 million $€ /$ year, while calcium carbonate production costs are 0.352 billion $€ /$ year. At optimal conditions, the total costs of this CCUS supply chain are 1.04 billion $€ /$ year. Capture and compression costs have the highest influence on the total costs, as also found in other 
supply chains reported in literature (Hasan et al., 2014; Kalyanarengan Ravi et al., 2017; Zhang et al., 2018). Calcium carbonate production costs also have a high influence on the total costs.

An economic analysis was carried out to evaluate the NPV and PB period. For this supply chain it is found that at the optimal conditions, the NPV is $€ 0.554$ trillion, while the PB period is 2.85 years. The system is economically profitable only when considering carbon tax $\left(€ 80 / \mathrm{tonCO}_{2}\right)$ and without considering other additional economic incentives.

The cost of polyurethane production is covered by confidentiality obligations, so a sensitivity analysis was developed in order to verify that the suggested value is not significant for the results obtained. In this sensitivity analysis different production costs, lower than the selling price (between $1349 € /$ ton and $2158 € /$ ton), were considered. The results of CCUS supply chain optimization are independent by the polyurethane production cost (a total cost of the supply chain of 1.04 billion $€ /$ year is obtained in all the different cases).

\subsection{Results of the CCUS supply chain with Scottish Offshore as storage site}

The optimal topology of this CCUS supply chain is reported in table 5.54 iterations were used to solve the model in 0.81 seconds.

\section{Table 5}

Topology of the CCUS supply chain for the UK with Scottish offshore as storage site

\begin{tabular}{ccc}
\hline $\mathbf{C O}_{2}$ source & $\mathbf{C O}_{2}$ capture technology/material & $\begin{array}{c}\mathbf{C O}_{2} \text { amount } \\
(\mathbf{M t o n} / \text { year })\end{array}$ \\
\hline Edinburgh & To storage & \\
\hline \multicolumn{3}{c}{ VSAWEI adsorption } \\
\hline Leeds & To utilization \\
\hline
\end{tabular}

The system consumes $61 \mathrm{Mton} / \mathrm{year}$ of carbon dioxide (in the four regions taken in the account in this study) and captures 6.4 Mton/year from those emissions, according to the established target. In this case, 4.84 Mton/year of captured carbon dioxide are sent to the storage section, while 1.56 Mton/year of captured carbon dioxide are sent to utilization. Edinburgh is the source selected in this case with VSA adsorption using WEI material for the selected capture process. In the utilization section, the Leeds carbon dioxide source is chosen by the model, with PZ absorption. Flue gas from Edinburgh has a carbon dioxide composition of 12 mol\%, slightly lower than the carbon dioxide composition of flue gas from Leeds (13 mol\%). However, the flue gas flow rate from Edinburgh is higher than that from Leeds. These results are in agreement with those reported in the literature by Hasan et al. (2012): at a comparable carbon dioxide composition (just above $10 \mathrm{~mol} \%$ ), for relatively low flue gas flow rate absorption technology is the suggested choice, while for relatively high flue gas flow rate VSA process is suggested due to lower costs. Regarding the capture material, MEA is selected due to the lower costs at lower carbon dioxide composition for a fixed amount of flue gas flow rate 
(Kalyanarengan Ravi et al., 2017). The WEI zeolite material is chosen because the flue gas flow rate of Leeds is not so high (Zhang et al., 2018).

As in the previous case study, the selected carbon dioxide source from which carbon dioxide is sent to storage to the nearest site in order to reduce carbon dioxide transportation costs. In the utilization section, carbon dioxide is used to produce calcium carbonate (1.4 Mton/year) at Lifford, Birmingham and at Fort William. A higher amount than the national demand is produced so it would need to be exported to other countries. The topology of CCUS supply chain is shown in figure 4.

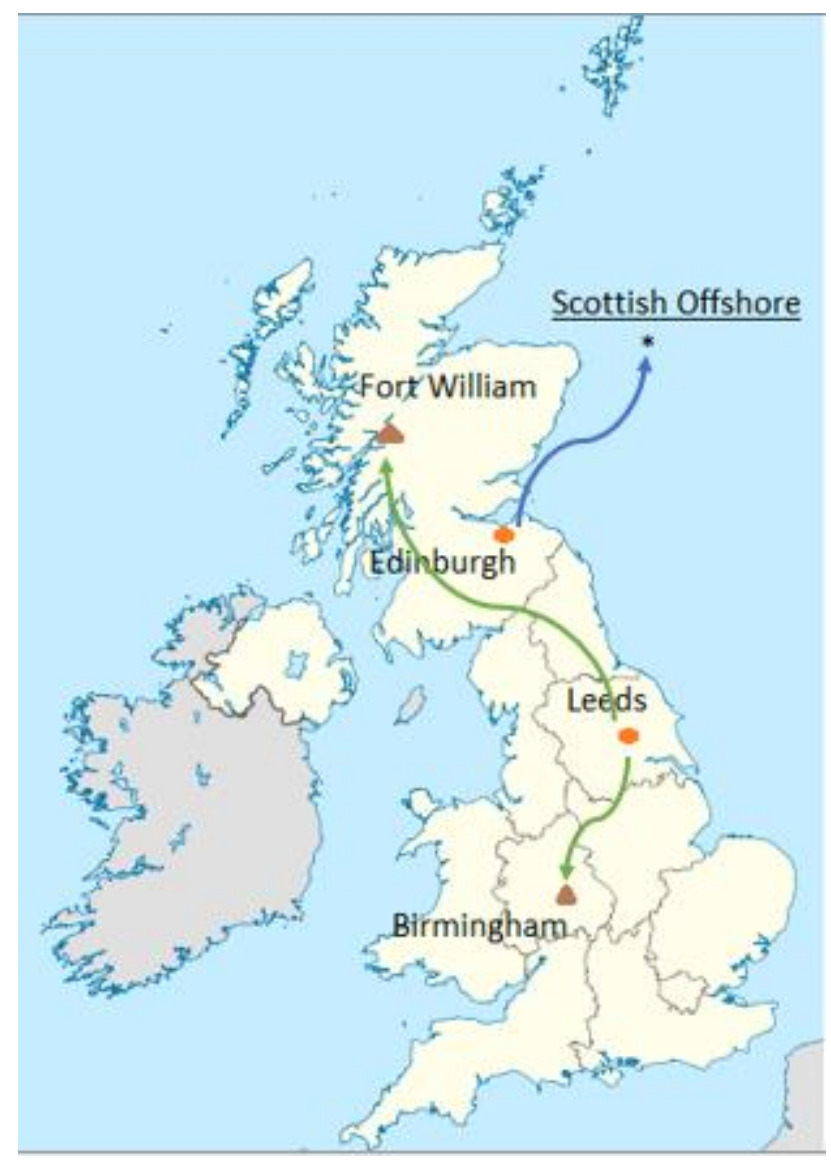

Figure 4 Topology of the optimized CCUS supply chain with Scottish Offshore as storage site ( carbon dioxide source, $*$ carbon dioxide storage, $\Delta$ calcium carbonate production site, $\longrightarrow$ to storage site, $\longrightarrow$ to utilization site)

The total costs of the supply chain are of $€ 0,425$ billion /year. Carbon dioxide capture and compression costs, carbon dioxide transportation costs, carbon dioxide storage costs and production costs of calcium carbonate are respectively of $€ 0.323$ billion /year, $€ 3.57$ million /year, $€ 7.76$ million /year and $€ 91.5$ million /year. Capture and compression costs have the highest influence on the total costs as in the previous case study and as reported elsewhere in the literature (Hasan et al., 2014; Kalyanarengan Ravi et al., 2017; Zhang et al., 2018). Capture and compression costs are followed by calcium carbonate production costs, carbon dioxide storage 
costs and carbon dioxide transportation costs. A more detailed economic analysis is carried out for the optimized system, in order to evaluate its profitability. NPV and PB are calculated and are respectively of 0.12 trillion€ and 5.27 years. In this analysis, only a carbon tax of $80 € /$ tonCO $_{2}$ was considered. A profitable system is obtained with a PB period of about 5 years.

\subsection{Results of the CCUS supply chain with Ormskirk sandstone storage site}

The optimal structure of the CCUS supply chain with the storage site in the East Irish Sea is reported in table 6. The optimal solution was found with 54 iterations in 0.8 seconds.

\section{Table 6}

Topology of the CCUS supply chain for the UK with Ormskirk Sandstone as storage site

\begin{tabular}{ccc}
\hline $\mathbf{C O}_{2}$ source & $\mathbf{C O}_{2}$ capture technology/material & $\begin{array}{c}\mathbf{C O}_{2} \text { amount } \\
(\text { Mton/year) }\end{array}$ \\
\hline Manchester & To storage & \\
\hline \multicolumn{3}{c}{ MEA Absorption } \\
\hline Leeds & To utilization & 0.46 \\
\hline
\end{tabular}

The system consumes 61 Mton/year of global carbon dioxide (in the four regions taken in the account in this study) and chooses to capture $6.4 \mathrm{Mton} / \mathrm{year}$ of these emissions from selected sources. A small amount of carbon dioxide is sent to storage: only 0.46 Mton/year are sent to the Ormskirk sandstone storage site. 5.94 Mton/year of carbon dioxide are sent to utilization section to produce calcium carbonate. As far as the storage section is concerned, Manchester, with a carbon dioxide composition of $14 \mathrm{~mol} \%$, is the selected source: once more it is the nearest source to the storage site and for this reason it is selected. For the utilization section, Leeds (i.e. the Yorkshire and the Humber region with a carbon dioxide composition of $13 \mathrm{~mol} \%$ ) is the chosen carbon dioxide source. For both of them absorption technology is the selected process. However, two different capture materials are selected: for the storage section MEA is selected while for the utilization section PZ solution is suggested. As in the first case study (the CCUS supply chain with Bunter Sandstone as storage site), absorption technology is selected due to a lower cost compared to other capture technologies (Leonzio et al., 2019a; Hasan et al., 2012b). However, for higher flow rates the PZ solution is the best material because it can ensure lower costs compared to MEA (Kalyanarengan Ravi et al., 2017). The optimized topology of this developed CCUS supply chain is shown in figure 5. 


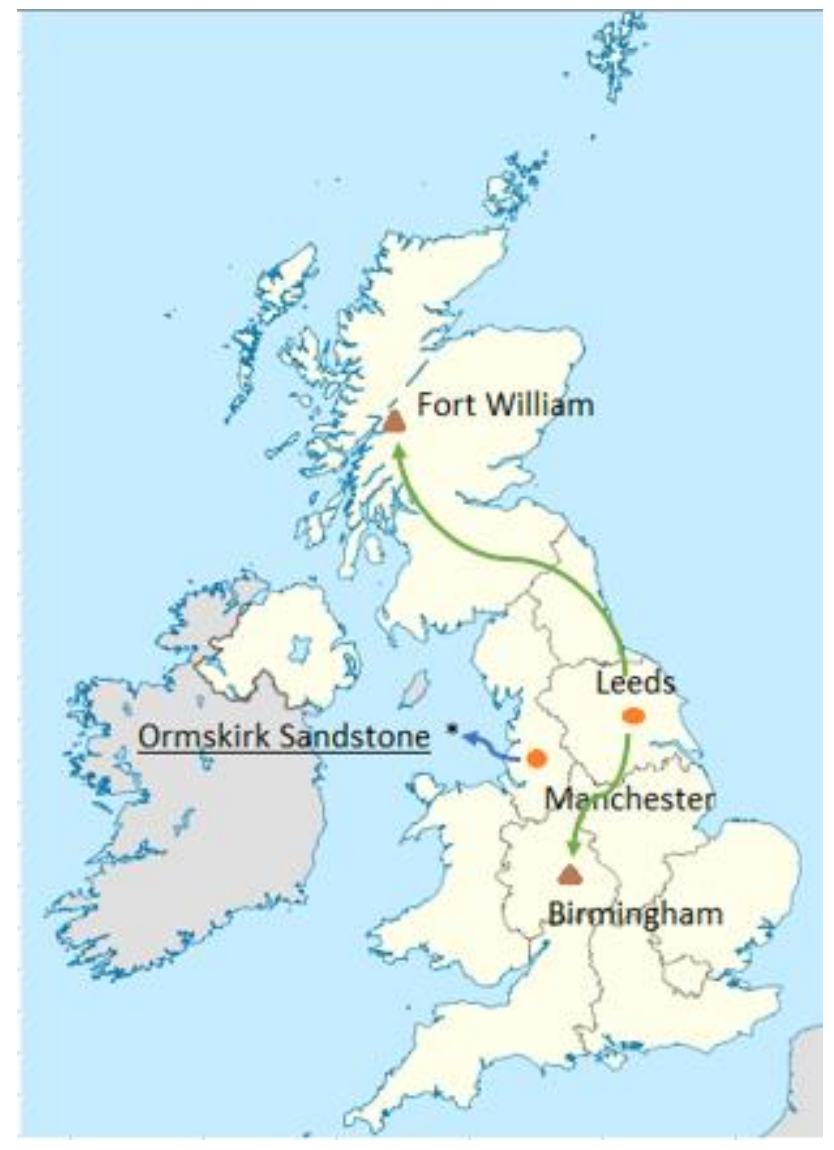

Figure 5 Topology of the optimized CCUS supply chain with Ormskirk Sandstone as storage site ( carbon dioxide source, $*$ carbon dioxide storage, $\boldsymbol{*}$ calcium carbonate production site, $\longrightarrow$ to storage site, $\longrightarrow$ to utilization site)

5,35 Mton/year of calcium carbonate are produced in the utilization section (at Lifford, Birmingham and at Fort William). Some of the produced calcium carbonate needs to be exported. Inside the optimized supply chain, carbon capture and compression costs are $€ 0,682$ billion /year, carbon dioxide transportation costs are $€ 2.18$ million/year, carbon dioxide storage costs are $€ 0.477$ million/year, while calcium carbonate production costs are $€ 0.349$ billion /year. The total costs of the optimized CCUS supply chain are equal to $€ 1,03$ billion /year. As already discussed, capture and compression costs mostly influence the total costs, followed by calcium carbonate production costs, carbon transportation costs and carbon dioxide storage costs. To evaluate the economic feasibility of the supply chain, the value of NPV and PB are found. As in previous cases, only a carbon tax is considered with a value of $€ 80 /$ tonCO $\mathrm{C}_{2}$. Results show that the NPV is equal to $€ 0.549$ trillion, while the PB time is 2.86 years. Profitability is ensured by the optimized CCUS supply chain with Ormskirk sandstone as storage site.

\subsection{Comparison of the developed CCUS supply chains}

A comparison among the different CCUS supply chains developed here is shown in table 7. 


\section{Table 7}

Comparison among the CCUS supply chains for the UK

\begin{tabular}{lccc}
\hline Storage site & Bunter Sandstone & Scottish offshore & Ormskirk Sandstone \\
\hline Treated $\mathrm{CO}_{2}$ (Mton/year) & 61 & 61 & 61 \\
Captured $\mathrm{CO}_{2}$ (Mton/year) & 6.4 & 6.4 & 6.4 \\
Minimum target for $\mathrm{CO}_{2}$ reduction (Mton/year) & 6.4 & 6.4 & 6.4 \\
Total costs of CCUS supply chain (billion€/year) & 1.04 & 0.425 & 1.03 \\
Produced compound & calcium carbonate & calcium carbonate & calcium carbonate \\
Amount of $\mathrm{CO}_{2}$-based product (Mton/year) & 5.4 & 1.4 & 5.35 \\
Net present value (trillion€/year) & 0.554 & 0.12 & 0.549 \\
Pay Back period (years) & 2.85 & 5.27 & 2.86 \\
Production cost $\mathrm{CO}_{2}$-based product (€/ton) $(*)$ & 193 & 304 & 193 \\
\hline
\end{tabular}

$\left.{ }^{*}\right)$ in this evaluation economic incentives and carbon tax are not considered

The systems consider the same global amount of carbon dioxide emissions of 61 Mton/year and capture the same amount of carbon dioxide (6.4 Mton/year) from selected sources according to the minimum target. Only calcium carbonate is produced in these supply chains due to the lower production costs to achieve the target for carbon dioxide reduction. 5.4 Mton/year, 1.4 Mton/year and 5.35 Mton/year of calcium carbonate are produced in the CCUS supply chain with Bunter Sandstone, Scottish Offshore and Ormskirk Sandstone as storage site respectively. This amount of calcium carbonate is higher than the national demand so a proportion should be exported and sold on the international market. The CCUS supply chain with the lowest cost is that with Scottish Offshore as storage site.. It was found that the CCUS supply chain with the highest value of NPV and the lowest PB time is that using Bunter Sandstone as storage site. For this structure the NPV is $€ 0.554$ trillion while the PB time is 2.85 years. Calcium carbonate production cost is $193 €$ /ton (without considering economic incentives or a carbon tax). The CCUS supply chain with Bunter Sandstone storage site is the best suggested solution according to the model.

\section{Conclusions}

CCUS supply chains will have a vital role for the UK to meet the 2030 target regarding carbon dioxide emissions and to move to a low carbon economy. The Government and the technical sector need to work together to build the frameworks to develop CCUS supply chains at large scale.

Due to the importance of these technologies, in this research three different CCUS supply chains for the UK were designed considering different storage sites. Products for which the production process has a high value for TRL were considered: calcium carbonate, tomato crops, concrete and polyurethane. In the projections for the year 2030, these products also meet a high national demand in terms of carbon dioxide consumed. Methanol and methane, obtained by hydrogenation reaction with renewable hydrogen, were also considered as in many literature studies about CCUS supply chains to check their comparative economic performance. Four regions (Wales, Scotland, Yorkshire and the Humber and the North West) with higher carbon dioxide emissions were 
considered in the structure of the supply chains. Bunter Sandstone, Scottish Offshore and Ormskirk sandstone were the considered storage sites for the different CCUS supply chains.

Results show that the CCUS supply chain with Bunter Sandstone as storage site is the most economically profitable system, due to the highest value of NPV (€0.554 trillion/year) and the lowest value of PB time (2.85 years), considering only the carbon tax, at a value of $€ 80 /$ ton $\mathrm{CO}_{2}$. The supply chain costs $€ 1.04$ billion/year and reduces 6.4 Mton/year of carbon dioxide emissions. The carbon dioxide captured is used to produce 5.4 Mton/year of calcium carbonate, an amount greater than the national demand, so a proportion should be exported. In the optimized supply chain Leeds is the reference city for the location of carbon source for utilization and storage sections. Due to lower costs, absorption technology and vacuum swing adsorption are selected for the capture process. All the CCUS supply chains considered are economically feasible considering also carbon tax.

It has been shown how using a mathematical model to find the optimal configuration of alternative carbon dioxide storage and utilization studies can be undertaken to find strategies for achieving the stringent $\mathrm{CO}_{2}$ reduction targets that the U.K. seeks to achieve. This approach should be used for CCUS infrastructure planning. In the future, research should be directed towards considering uncertainties, market dynamics and social aspects. This last aspect in particular has not received much attention in the literature. 


\section{Acknowledgment}

This research did not receive any specific grant from funding agencies in the public, commercial, or not-forprofit sectors. Grazia Leonzio would like to thank the University of L'Aquila for the $\mathrm{PhD}$ grant and the additional Erasmus grant to spend a six months research period at the University College London, UK. 


\section{References}

Alberici, S., Noothout, P., Mir, G.U.R., Stork, M., Wiersma (Ecofys), F., with technical input from Mac Dowell, N., Shah, N., Fennell P., Assessing the potential of CO2 utilization in the UK, Final report, Ecofys 2017 by order of: UK Department for Business, Energy \& Industrial Strategy (BEIS).

Ancona, M.A., Antonucci, V., Branchini, L., Catena, F., De Pascale, A., Di Blasi, A., Ferraro, M., Italiano, C., Melino, F., Vita, A., 2019. Thermal integration of a high-temperature co-electrolyzer and experimental methanator for Power-to-Gas energy storage system, Energy Conversion and Management 186, 140-155. https://doi.org/10.1016/i.enconman.2019.02.057

Babaei, M., Govindan, R., Korre, A., Shi, J.Q., Durucan, S., Quinn, M., 2016 Calculation of pressure- and migration-constrained dynamic CO2 storage capacity of the North Sea Forties and Nelson dome structures. International Journal of Greenhouse Gas Control, 53. 127-140. https://doi.org/10.1016/j.ijggc.2016.07.044

Babaei, M., Govindan, R., Korre, A., Shi, J.Q., Durucana, S., Quinn, M., McCormac, M., 2014. CO2 storage potential at Forties oilfield and the surrounding Paleocene sandstone aquifer accounting for leakage risk through abandoned wells, Energy Procedia 63, 5164 - 5171. https://doi.org/10.1016/j.egypro.2014.11.546

Bide, T., Brown, T.J., Idoine, N., Mankelow, J.M., 2019. United Kingdom Minerals Yearbook 2018, British Geological Survey Open Report, OR/19/018, 63 pp.

Broek, M.V.D., Brederode, E., Ramírez, A., Kramers, L., Kuip, M.V.D., Wildenborg, T., Turkenburg, W., Faaij, A., 2010. Environmental modelling \& software designing a cost-effective CO2 storage infrastructure using a GIS based linear optimization energy model. Environ. Modell. Softw. 25 (12), 1754-1768, http://dx.doi.org/10.1016/j.envsoft.2010.06.015.

Budinis, S., Krevor, S., Mac Dowell, N., Brandon, N., Hawkes, A., 2018. An assessment of CCS costs, barriers and potential. Energy Strateg. Rev. 22, 61-81. https://doi.org/10.1016/j.esr.2018.08.003

Bentham, M., An assessment of carbon sequestration potential in the UK - Southern North Sea case study, Tyndall Centre for Climate Change Research, 2006.

Cavanagh, A., Ringrose, P., 2014. Improving oil recovery and enabling CCS: a comparison of offshore gasrecycling in Europe to CCUS in North America, Energy Procedia 63, 7677-7684. https://doi.org/10.1016/j.egypro.2014.11.801

Dahowski, R., Dooley, J., Davidson, C., Bachu, S., Gupta, N., 2004. A CO2 Storage Supply Curve for North America, Proceedings of the 7. international conference on greenhouse gas control technologies

Department of Business, Energy and Industrial Strategy, Local authority carbon dioxide emissions estimates 2016, Statistical Release: National Statistics, 26 June 2018.

Department of Business, Energy and Industrial Strategy, 2018 UK Greenhouse gas emissions, provisional figures, Statistical Release: National Statistics, 28 March 2019.

Department of Energy \& Climate Change, 2010, CO2 Storage in the UK - Industry Potential

Dlugokencky, E., Tans, P., NOAA/ESRL, 2018. www.esrl.noaa.gov/gmd/ccgg/trends/.

Kwak, D.H., Kim, J.K., 2017. Techno-economic evaluation of CO2 enhanced oil recovery (EOR) with the optimization of $\mathrm{CO} 2$ supply, International Journal of Greenhouse Gas Control, 58, 169-184. https://doi.org/10.1016/j.ijggc.2017.01.002 
Dong, K., Jiang, H., Sun, R., Dong, X., 2019. Driving forces and mitigation potential of global CO2 emissions from 1980 through 2030: Evidence from countries with different income levels, Science of the Total Environment 649, 335-343. https://doi.org/10.1016/i.scitotenv.2018.08.326

Durmaz, T., 2018. The economics of CCS: why have CCS technologies not had an international breakthrough? Renew. Sustain. Energy Rev. 95, 328-340. https://doi.org/10.1016/j.rser.2018.07.007

European Commission, 2011. Energy Efficiency Plan 2011 (Brussels).

Fan, J.L., Xu, M., Yang, L., Zhangd, X., Lie, F., 2019. How can carbon capture utilization and storage be incentivized in China? A perspective based on the 45Q tax credit provisions, Energy Policy 132, 1229-1240. https://doi.org/10.1016/j.enpol.2019.07.010

Freund, P., 2003. Making deep reductions in CO2 emissions from coal-fired power plants using capture and storage of CO2. Proc. IME J. Power Energy 217 (1), 1-7. https://doi.org/10.1243/095765003321148628

Gammer, D., A. Green, ETI, S. Holloway, BGS, Smith, G., Senergy, The Energy Technologies Institute's UK CO2 Storage Appraisal Project (UKSAP), SPE Offshore Europe Oil and Gas Conference and Exhibition held in Aberdeen, UK, 6-8 September 2011.

Gounaris, C.E., Rajendran, K., Kevrekidis, I.G., Floudas, C.A., 2016. Designing Networks: A Mixed-Integer Linear Optimization Approach, Networks, 68 (6) 283-301, 10.1002/net.21699

Hasan, M.M.F., Boukouvala, F., First, E.L., Floudas, C.A., 2014. Nationwide, Regional, and Statewide CO2 Capture, Utilization, and Sequestration Supply Chain Network Optimization, Ind. Eng. Chem. Res. 53, 7489-7506. https://doi.org/10.1021/ie402931c

Hasan, M.M.F., First, E.L., Boukouvala, F., Floudas, C.A., 2015. A multi-scale framework for CO2capture, utilization, andsequestration: CCUS and CCU, Computers and Chemical Engineering 81, 2-21. https://doi.org/10.1016/j.compchemeng.2015.04.034

Hasan, M.M.F., Baliban, R.C., Elia, J.A., Floudas, C.A., 2012a. Modeling, simulation, and optimization of postcombustion $\mathrm{CO} 2$ capture for variable feed concentration and flowrate. 1. Chemical absorption and membrane processes. Ind Eng Chem Res, 51, (48), 15642-64. https://doi.org/10.1021/ie301571d

Hasan, M.M.F., Baliban, R.C., Elia, J.A., Floudas, C.A., 2012b. Modeling, simulation, and optimization of postcombustion $\mathrm{CO} 2$ capture for variable feed concentration and flow rate.2. Pressure swing adsorption and vacuum swing adsorption processes. Ind EngChem Res., 51, (48), 15665-82. https://doi.org/10.1021/ie301572n

Hank, C., Gelpke, S., Schnabl, A., White, R.J., Full, J., Wiebe, N., Smolinka, T., Schaadt, A., Henning, H.M., and Hebling, C., 2018. Economics \& carbon dioxide avoidance cost of methanol production based on renewable hydrogen and recycled carbon dioxide - power-to-methanol, Sustainable Energy Fuels, 2, 12441261. 10.1039/C8SE00032H

Hendriks, C.A., 1994. Carbon Dioxide Removal from coal-Fired power plant. In department of science, technology, and society. Utrecht University. Utrecht, Netherlands. 10.1007/978-94-011-0301-5

Huang, Y., Zheng, Q.P., Fan, N., Aminian, K., 2014. Optimal scheduling for enhanced coal bed methane production through CO2injection. Appl. Energy 113, 1475-1483. https://doi.org/10.1016/j.apenergy.2013.08.074

https://data.worldbank.org/indicator/EN.ATM.CO2E.KT?end=2014\&start=1960\&view=chart

http://naei.beis.gov.uk/reports/reports?section id=4

http://www.defra.gov.uk/statistics/foodfarm/landuselivestock/bhs/ 
https://www.holanda.es/media/106863/5)\%20n.\%20van\%20der\%20velden-

producci\%C3\%B3n\%20\%E2\%80\%9Clocal-for-

local\%E2\%80\%9D\%20de\%20tomates\%20en\%20invernadero\%20posibilidades\%20y\%20comentarios.pdf

http://www.prea.co.uk/

https://www.basf.com/gb/en/who-we-are/Locations/Alfreton.html

https://apsgroup.uk.com/discover

https://mineralproducts.org/documents/Facts-at-a-Glance-2018.pdf

https://www.hanson.co.uk/en/hanson-location-finder

http://www.calcium-carbonate.org.uk/uklocations.asp

https://www.reportlinker.com/data/series/F030qLS3ZB8

https://www.eia.gov/beta/international/analysis.php?iso=GBR

https://www.ons.gov.uk/businessindustryandtrade/manufacturingandproductionindustry/datasets/ukmanufact urerssalesbyproductprodcom

http://www.britishgrowers.org/british-growing/

https://www.theccc.org.uk/wp-content/uploads/2015/11/Fifth-Carbon-Budget_Ch2_Overview-of-climate science-and-international-circumstances.pdf

https://www.hanson.co.uk/en/hanson-location-finder

http://www.calcium-carbonate.org.uk/uklocations.asp

IEA, CO2 Emissions from Fuel Combustion, 2016

IEA (International Energy Agency), 2019. Global energy \& $\quad$ CO2 status report. https:// www.iea.org/geco/emissions/.

IPCC, Climate Change, 2014: synthesis report, in: R.K. Pachauri, L.A. Meyer (Eds.), Contribution of Working Groups I, II and III to the Fifth Assessment Report of the Intergovernmental Panel on Climate Change, IPCC, Geneva, Switzerland, 2014, p. 155.

Kalyanarengan Ravi, N., Van Sint Annaland, M., Fransoo, J.C., Grievink, J., Zondervan, E., 2017. Development and implementation of supply chain optimization framework for $\mathrm{CO} 2$ capture and storage in the Netherlands. $\quad$ Computer $\quad$ Chemical $\quad$ Engineering $\quad 102, \quad 40-51$. https://doi.org/10.1016/j.compchemeng.2016.08.011

Kirk. K.L., 2005. Potential for storage of carbon dioxide in the rocks beneath the East Irish Sea. British Geological Survey Internal Report, CR/05/127N. 24pp.

Kuuskraa, V.A., Godec, M.L., Dipietro, P., 2013. CO2 Utilization from "Next Generation" CO2 Enhanced Oil Recovery Technology, Energy Procedia 37, 6854 - 6866. https://doi.org/10.1016/j.egypro.2013.06.618

Klokk, Ø., Schreiner, P.F., Pages-Bernaus, A., Tomasgard, A., 2010. Optimizing a CO2 value chain for the Norwegian Continental Shelf, Energy Policy 38, 6604-6614. https://doi.org/10.1016/j.enpol.2010.06.031

Kolstera, C., Agadad, S., Mac Dowell, N., Krevord, S., 2018. The impact of time-varying CO2 injection rate on large scale storage in the UK Bunter Sandstone, International Journal of Greenhouse Gas Control 68, 7785. https://doi.org/10.1016/j.ijggc.2017.10.011 
Kühn, M., Förster, A., Großmann, J., Lillie, J., Pilz, P., Reinicke, K.M., Schäfer, D., Tesmer, M. and CLEAN Partners. 2013. The Altmark Natural Gas Field is prepared for the Enhanced Gas Recovery Pilot Test with CO2. Energy Procedia. (37), 6777-6785. https://doi.org/10.1016/i.egypro.2013.06.611

Lainez-Aguirrea, J.M., Pérez-Fortes, M., Puigjaner, L., 2017. Economic evaluation of bio-based supply chains with CO2 capture and utilization, Computers and Chemical Engineering 102, 213-225. https://doi.org/10.1016/j.compchemeng.2016.09.007

Li, Z., Zhang, D.J., Ma, L.W., West, L., Ni, W.D., 2011. The necessity of and policy suggestions for implementing a limited number of large scale, fully integrated CCS demonstrations in China. Energy Policy 39 (9), 5347-5355. https://doi.org/10.1016/j.enpol.2011.05.029

Lee, S.Y., Lee, I.B., Han, J. 2019. Design under uncertainty of carbon capture, utilization and storage infrastructure considering profit, environmental impact, and risk preference, Applied Energy 238, 34-44. https://doi.org/10.1016/j.apenergy.2019.01.058

Leonzio, G., Foscolo, P.U., Zondervan, E., 2019b. Sustainable utilization and storage of carbon dioxide: analysis and design of an innovative supply chain, Computers and Chemical Engineering, 131, 106569. https://doi.org/10.1016/i.compchemeng.2019.106569

Leonzio, G., Foscolo, P.U., Zondervan, E., 2019a. An outlook towards 2030: Optimization and design of a CCUS supply chain in Germany, Computers and Chemical Engineering 125, 499-513. https://doi.org/10.1016/j.compchemeng.2019.04.001

Leonzio, G., Zondervan, E., 2019. Analysis and optimization of carbon supply chain integrated by power to gas process in Italy, Journal of Cleaner Production, under review.

Mathisena, A., Skagestad, R., 2017. Utilization of CO2 from emitters in Poland for CO2-EOR, Energy Procedia 114, 6721 - 6729. https://doi.org/10.1016/j.egypro.2017.03.1802

Middleton, R.S., Levine, J., Bielicki, J., Carey, J.W., Viswanathan, H.S., Stauffer, P.H., 2015. Jumpstarting commercial-scale $\mathrm{CO} 2$ capture and storage with ethylene production and enhanced oil recovery in the U.S. Gulf, Greenhouse Gases: Science and Technology, 5, 3, 241-253. https://doi.org/10.1002/ghg.1490

Miret, C., Chazara, P., Montastruc, L., Negny, S., Domenech, S., 2016. Design of bioethanol green supply chain: comparison between first and second generation biomass concerning economic, environmental and social criteria. Comput. Chem. Eng. 85, 16-35, http://dx.doi.org/10.1016/j.compchemeng.2015.10.008

Meunier, N., Chauvy, R., Mouhoubi, S., Thomas, D., De Weireld, G. 2020. Alternative production of methanol from industrial CO2, Renewable Energy 146, 1192-1203. https://doi.org/10.1016/j.renene.2019.07.010

Nguyen, T.B.H., Zondervan, E. 2018. Ionic Liquid as a Selective Capture Method of CO2 from Different Sources: Comparison with MEA, ACS Sustainable Chemistry \& Engineering, 6 (4), 4845-4853.

10.1021/acssuschemeng.7b04247

Nguyen T.B.H., Reisemann S.G., Zondervan. E., Development of a conceptual process for CO2 capture from flue gases using ionic liquid. Proceedings of the 27th European Symposium on Computer Aided Process Engineering - ESCAPE 27 October 1st - 5th. 2017. Barcelona. Spain.

Ochoa Bique, A., Nguyen, T.B.H., Leonzio, G., Galanopoulos, C., Zondervan, E. 2018. Integration of carbon dioxide and hydrogen supply chains, Computer Aided Chemical Engineering, 43, 1413-1418.

Patricio, J., Angelis-Dimakisb, A., Castillo-Castillo, A., Kalmykova, Y., Rosado, L., 2017. Region prioritization for the development of carbon capture and utilization technologies, Journal of CO2 Utilization 17, 50-59. https://doi.org/10.1016/j.jcou.2016.10.002 
Pérez-Fortes, M., Laínez-Aguirre, J.M., Puigjaner, L., 2017. Optimal bio-based supply chain with carbon capture and use: An economic and environmental approach, Computer Aided Chemical Engineering, 40, 2665 2670. https://doi.org/10.1016/B978-0-444-63965-3.50446-3.

Quarton, C.J., Samsatli, S., 2020. The value of hydrogen and carbon capture, storage and utilisation in decarbonising energy: Insights from integrated value chain optimization, Applied Energy 257, 113936. https://doi.org/10.1016/j.apenergy.2019.113936

Rahmawati, S.D., Hoda, M.F., Kuntadi, A., 2015. CO2 injection project analysis using application of integrated model and optimization. In: SPE Middle East Oil and Gas Show and Conference, MEOS, Proceedings, 1916-1926

Reichert F., 2012 Wind-to-Gas-to-Money? Economics and Perspectives of the Power-to-Gas Technology. Aalborg University Department of Development and Planning MSc (Eng) Sustainable Energy Planning and Management. master thesis.

Rogelj, J., den Elzen, M., H€ohne, N., Fransen, T., Fekete, H., Winkler, H., Schaeffer, R., Sha, F., Riahi, K., Meinshausen, M., 2016. Paris Agreement climate proposals need a boost to keep warming well below $2 \mathrm{C}$. Nature 534, 631-639. https://doi.org/10.1038/nature18307

Saito, A., Itaoka, K., Akai, M., 2019. Those who care about CCS — results from a Japanese survey on public understanding of CCS. Int. J. Greenh. Gas Control 84, 121-130. https://doi.org/10.1016/j.ijggc.2019.02.014

Serpa, J., Morbee, J., Tzimas, E., 2011. Technical and Economic Characteristics of a CO2 Transmission Pipeline Infrastructure, doi:10.2790/30861.

Sheldon, D., 2017. Methanol Production - A Technical History A review of the last 100 years of the industrial history of methanol production and a look into the future of the industry, Johnson Matthey Technology Review, 61, 3, 172-182, 2017.

Sun L., Chen W. 2017. Development and application of a multi-stage CCUS source-sink matching model. Appl Energy 185, 1424-32. https://doi.org/10.1016/j.apenergy.2016.01.009

Sun, L., Dou, H., Li, Z., Hu, Y., Hao, X., 2018. Assessment of CO2 storage potential and carbon capture, utilization and storage prospect in China, Journal of the Energy Institute 91, 970-977.

Suicmez, V.S., 2019. Feasibility study for carbon capture utilization and storage (CCUS) in the Danish North Sea, Journal of Natural Gas Science and Engineering 68, 102924. https://doi.org/10.1016/i.jngse.2019.102924

Tapia, J.F.D., Lee, J.Y., Ooi, R.E.H., Foo, D.C.Y., Tan, R.R., 2016a. Optimal CO2 allocation and scheduling in enhanced oil recovery (EOR) operations. Appl. Energy 184, 337-345. https://doi.org/10.1016/i.apenergy.2016.09.093

Tapia, J.F.D., Lee, J.Y., Ooi, R.E.H., Foo, D.C.Y., Tan, R.R., 2016b. Planning and scheduling of CO2 capture, utilization and storage (CCUS) operations as a strip packing problem. Process Saf. Environ. Prot. 104, 358372. https://doi.org/10.1016/j.psep.2016.09.013

Von Stechow, C., Watson, J., Praetorius, B., 2011. Policy incentives for carbon capture and storage technologies in Europe: a qualitative multi-criteria analysis. Glob. Environ. Chang. 21 (2), 346-357. https://doi.org/10.1016/j.gloenvcha.2011.01.011

von der Assen, N., Sternberg, A., Katelhon A., and Bardow, A., 2015. Environmental potential of carbon dioxide utilization in the polyurethane supply chain, Faraday Discuss., 183, 291-307. 10.1039/C5FD00067J

www.nhc.noaa.gov 
Yao, X., Zhong, P., Zhang, X., Zhud, L. 2018. Business model design for the carbon capture utilization and storage (CCUS) project in China, Energy Policy 121, 519-533. https://doi.org/10.1016/i.enpol.2018.06.019

Yue D., You F., 2015, Integration of geological sequestration and microalgae biofixation supply chains for better greenhouse gas emission abatement, Chemical Engineering Transactions, 45, 487-492 DOI:10.3303/CET1545082

Yue, D., You, F., Snyder, S.W., 2014. Biomass-to-bioenergy and biofuel supply chain optimization: overview, key issues and challenges. Comput. Chem. Eng. 66, 36-56, http://dx.doi.org/10.1016/j.compchemeng.2013.11.016.

Yi, Q., Zhao, Y., Huang, Y., Wei, G., Hao, Y., Feng, J. 2018. Usama Mohamed, Mohamed Pourkashanian, William Nimmo, Wenying Li, Life cycle energy-economic-CO2 emissions evaluation of biomass/coal, with and without $\mathrm{CO} 2$ capture and storage, in a pulverized fuel combustion power plant in the United Kingdom, Applied Energy 225, 258-272. https://doi.org/10.1016/j.apenergy.2018.05.013

Yu, S., Horinga, J., Liu, Q., Dahowski, R., Davidson, C., Edmonds, J., Liu, B., Mcjeona, H., McLeod, J., Patel, P., Clarke, L. 2019. CCUS in China's mitigation strategy: insights from integrated assessment modeling, International Journal of Greenhouse Gas Control 84, 204-218. https://doi.org/10.1016/i.ijggc.2019.03.004

Zappa, W., 2014. Pilot-scale Experimental Work on the Production of Precipitated Calcium Carbonate (PCC) from Steel Slag for CO2 Fixation, PhD thesis.

Li, Z., Zhang, D.J., Ma, L.W., West, L., Ni, W.D., 2011. The necessity of and policy suggestions for implementing a limited number of large scale, fully integrated CCS demonstrations in China. Energy Policy 39 (9), 5347-5355. https://doi.org/10.1016/j.enpol.2011.05.029

Zhang, A., Liu, L., Zhang, L., Zhuang, Y., Du, J. 2018. An optimization model for carbon capture utilization and storage supply chain: A case study in Northeastern China, Applied Energy 231, 194-206. https://doi.org/10.1016/j.apenergy.2018.09.129 


\section{Nomenclature}

Indices

i carbon dioxide sources

j carbon dioxide capture system

$\mathrm{k}$ carbon dioxide storage sites and complementary utilization section

m methanol production sites

$\mathrm{g}$ methane production sites

p polyurethane production sites

$\mathrm{t}$ tomato production sites

c concrete production sites

$\mathrm{d}$ calcium carbonate production sites

\section{Abbreviations}

AIMMS Advanced Interactive Multidimensional Modeling System

CCUS carbon capture utilization and storage

CCS carbon capture and storage

$\mathrm{CO}_{2}$-ECBM carbon dioxide enhanced coal bed methane

$\mathrm{CO}_{2}$-EOR carbon dioxide enhanced oil recovery

EU European Union

IC maximum injection capacity per well (ton)

IL ionic liquid

MEA monoethanolamine

MILP mixed integer linear programming

MINLP a mixed integer non linear programming

NPV net present value

PB pay back period

PSA pressure swing adsorption

PZ piperazine

TH time horizon

TRL technology readiness level

VSA vacuum swing adsorption 


\section{Continuous variables}

$\mathrm{CC}_{\mathrm{i}, \mathrm{j}, \mathrm{k}}$ capture and compression cost of carbon dioxide captured from source $\mathrm{i}$ with technology $\mathrm{j}$ sent to storage/utilization $\mathrm{k}(€ /$ year)

$\mathrm{CDC}_{\mathrm{i}, \mathrm{j}, \mathrm{k}}$ flue gas dehydration costs for carbon dioxide captured from source $\mathrm{i}$ with technology $\mathrm{j}$ sent to storage/utilization $\mathrm{k}(€ /$ year)

$\mathrm{CIC}_{\mathrm{i}, \mathrm{j}, \mathrm{k}}$ investment capture and compression cost of carbon dioxide captured from source $\mathrm{i}$ with technology $\mathrm{j}$ sent to storage/utilization $\mathrm{k}(€ /$ year)

$\mathrm{COC}_{\mathrm{i}, \mathrm{j}, \mathrm{k}}$ operating capture and compression cost of carbon dioxide captured from source $\mathrm{i}$ with technology $\mathrm{j}$ sent to storage/utilization $\mathrm{k}(€ /$ year)

$\mathrm{CP}_{\mathrm{c}}$ concrete production costs $(€ /$ year $)$

$\mathrm{CP}_{\mathrm{t}}$ tomato production costs $(€ /$ year)

$\mathrm{CP}_{\mathrm{p}}$ polyurethane production costs $(€ /$ year $)$

$\mathrm{CP}_{\mathrm{d}}$ calcium carbonate production costs $(€ /$ year $)$

$\mathrm{CP}_{\mathrm{m}}$ methanol production costs $(€ /$ year $)$

$\mathrm{CP}_{\mathrm{g}}$ methane production costs $(€ /$ year $)$

$\mathrm{Fr}_{\mathrm{i}, \mathrm{j}, \mathrm{k}}$ fraction of captured carbon dioxide from source $\mathrm{i}$ with technology $\mathrm{j}$ sent to storage site $\mathrm{k}$

Utilization $_{\mathrm{i}, \mathrm{j}, \mathrm{k}}$ fraction of captured carbon dioxide from source $\mathrm{i}$ with technology $\mathrm{j}$ sent to overall utilization site $\mathrm{k}$

Methanol $_{i, j, m}$ fraction of captured carbon dioxide from source $i$ with technology $j$ sent to methanol production site $\mathrm{m}$

Methane $_{\mathrm{i}, \mathrm{j}, \mathrm{g}}$ fraction of captured carbon dioxide from source $\mathrm{i}$ with technology $\mathrm{j}$ sent to methane production site $\mathrm{g}$

Polyurethane $\mathrm{i}_{\mathrm{i}, \mathrm{p}}$ fraction of captured carbon dioxide from source $\mathrm{i}$ with technology $\mathrm{j}$ sent to polyurethane production site $\mathrm{p}$

$\mathrm{TC}_{\mathrm{i}, \mathrm{j}, \mathrm{k}, \mathrm{c}, \mathrm{t}, \mathrm{p}, \mathrm{d}, \mathrm{m}, \mathrm{g}}$ total transport cost of carbon dioxide captured from source i through capture technology $\mathrm{j}$ sent to storage site $\mathrm{k} /$ concrete production site c/tomato production site $\mathrm{t} /$ polyurethane production site $\mathrm{p} / \mathrm{calcium}$ carbonate production site $\mathrm{d} /$ methanol production site $\mathrm{m} /$ methane production site $\mathrm{g}(€ /$ year)

$\mathrm{TIC}_{\mathrm{i}, \mathrm{j}, \mathrm{k}, \mathrm{c}, \mathrm{t}, \mathrm{d}, \mathrm{m}, \mathrm{g}}$ investment transport cost of carbon dioxide captured from source $\mathrm{i}$ through capture technology $\mathrm{j}$ sent to storage site $\mathrm{k} /$ concrete production site c/tomato production site $\mathrm{t} /$ polyurethane production site $\mathrm{p} /$ calcium carbonate production site $\mathrm{d} /$ methanol production site $\mathrm{m} /$ methane production site $\mathrm{g}(€ /$ year)

TOC $_{\mathrm{i}, \mathrm{j}, \mathrm{k}, \mathrm{c}, \mathrm{t}, \mathrm{d}, \mathrm{d}, \mathrm{m}, \mathrm{g}}$ operating transport cost of carbon dioxide captured from source $\mathrm{i}$ through capture technology $\mathrm{j}$ sent to storage site $\mathrm{k} /$ concrete production site c/tomato production site t/polyurethane production site $\mathrm{p} /$ calcium carbonate production site $\mathrm{d} /$ methanol production site $\mathrm{m} /$ methane production site $\mathrm{g}(€ /$ year)

Tomato $\mathrm{i}_{\mathrm{i}, \mathrm{j}, \mathrm{f}}$ fraction of captured carbon dioxide from source $\mathrm{i}$ with technology $\mathrm{j}$ sent to tomato growing $\mathrm{t}$ Concrete $\mathrm{i}_{\mathrm{i}, \mathrm{j}, \mathrm{c}}$ fraction of captured carbon dioxide from source $\mathrm{i}$ with technology $\mathrm{j}$ sent to concrete curing $\mathrm{c}$ CalciumCarbonate $\mathrm{i}_{\mathrm{i}, \mathrm{d}, \mathrm{d}}$ fraction of capture carbon dioxide from source $\mathrm{i}$ with technology $\mathrm{j}$ sent to calcium carbonate production site $\mathrm{d}$

$\mathrm{SC}_{\mathrm{k}}$ total carbon dioxide storage cost for storage site $\mathrm{k}(€ /$ year) 
$\mathrm{SIC}_{\mathrm{k}}$ investment carbon dioxide storage cost for storage site $\mathrm{k}(€ /$ year)

$\mathrm{SOC}_{\mathrm{k}}$ operating carbon dioxide storage cost for storage site $\mathrm{k}(€ /$ year$)$

\section{Binary variables}

$\mathrm{X}_{\mathrm{i}, \mathrm{j}, \mathrm{k}} 1$ if carbon dioxide is captured from source $\mathrm{i}$ with technology $\mathrm{j}$ and sent to storage site $\mathrm{k}$, otherwise 0

$\mathrm{Y}_{\mathrm{i}, \mathrm{j}, \mathrm{k}} 1$ if carbon dioxide is capture from source $\mathrm{i}$ with technology $\mathrm{j}$ and sent to storage/utilization site $\mathrm{k}$, otherwise 0

\section{Parameters}

b parameter in investment storage costs

$\mathrm{C}_{\mathrm{k}}{ }^{\text {max }}$ maximum storage capacity at the storage site $\mathrm{k}$ (ton)

$\mathrm{CR}^{\mathrm{min}}$ minimum target for overall carbon dioxide reduction (ton/year)

$\mathrm{CS}_{\mathrm{i}}$ total carbon dioxide emission from source i (ton/year)

$\mathrm{D}_{\mathrm{i}, \mathrm{k}}$ distance from carbon source $\mathrm{i}$ to storage site $\mathrm{k}(\mathrm{km})$

$\mathrm{D}_{\mathrm{i}, \mathrm{c}}$ distance from carbon source i to concrete production site $\mathrm{c}(\mathrm{km})$

$\mathrm{D}_{\mathrm{i}, \mathrm{t}}$ distance from carbon source $\mathrm{i}$ to tomato growing site $\mathrm{t}(\mathrm{km})$

$\mathrm{D}_{\mathrm{i}, \mathrm{p}}$ distance from carbon source $\mathrm{i}$ to polyurethane production site $\mathrm{p}(\mathrm{km})$

$\mathrm{D}_{\mathrm{i}, \mathrm{d}}$ distance from carbon source $\mathrm{i}$ to calcium carbonate production site $\mathrm{d}(\mathrm{km})$

$\mathrm{D}_{\mathrm{i}, \mathrm{m}}$ distance from carbon source $\mathrm{i}$ to methanol production site $\mathrm{m}(\mathrm{km})$

$\mathrm{D}_{\mathrm{i}, \mathrm{g}}$ distance from carbon source $\mathrm{i}$ to methane production site $\mathrm{g}(\mathrm{km})$

$\mathrm{d}_{\text {well }}$ depth of well $(\mathrm{km})$

$\mathrm{F}_{\mathrm{i}}$ total flue gas flow rate from source $\mathrm{i}(\mathrm{mol} / \mathrm{s})$

$\mathrm{F}_{\mathrm{i}, \mathrm{j}, \mathrm{k}}$ flue gas flow rate from source i trough capture technology $\mathrm{j}$ to storage/utilization section $\mathrm{k}(\mathrm{mol} / \mathrm{s})$

$F_{t}$ Terrestrial factor

$\mathrm{m}$ parameter in investment storage costs

$\mathrm{m}_{\mathrm{I}, \mathrm{j}}$ parameter in investment capture and compression costs for technology $\mathrm{j}$

$\mathrm{m}_{\mathrm{o}, \mathrm{j}}$ parameter in operating capture and compression costs for technology $\mathrm{j}$

$\mathrm{n}_{\mathrm{I}, \mathrm{j}}$ parameter in capture and compression investment costs for technology $\mathrm{j}$

$\mathrm{n}_{\mathrm{o}, \mathrm{j}}$ parameter in capture and compression operating costs for technology $\mathrm{j}$

$\mathrm{X}_{\mathrm{i}, \mathrm{j}, \mathrm{c}} 1$ if Concrete $\mathrm{e}_{\mathrm{i}, \mathrm{j}, \mathrm{c}}$ is higher than 0,0 otherwise

$\mathrm{X}_{\mathrm{i}, \mathrm{j}, \mathrm{t}} 1$ if Tomato $\mathrm{i}_{\mathrm{i}, \mathrm{t}, \mathrm{t}}$ is higher than 0,0 otherwise

$\mathrm{X}_{\mathrm{i}, \mathrm{j}, \mathrm{d}} 1$ if CalciumCarbonate $\mathrm{i}_{\mathrm{i}, \mathrm{d}}$ is higher than 0,0 otherwise 
$\mathrm{X}_{\mathrm{i}, \mathrm{j}, \mathrm{m}} 1$ if Methanol $_{\mathrm{i}, \mathrm{j}, \mathrm{m}}$ is higher than 0,0 otherwise

$\mathrm{X}_{\mathrm{i}, \mathrm{j}, \mathrm{g}} 1$ if Methane $_{\mathrm{i}, \mathrm{j}, \mathrm{g}}$ is higher than 0,0 otherwise

$\mathrm{x}_{\mathrm{CO} 2}$, $\mathrm{i}$ Carbon dioxide molar fraction from source $\mathrm{i}$

$\mathrm{XL}_{\mathrm{i}}$ lowest composition processing limit for capture technology $\mathrm{j}$ (mol\%)

$\mathrm{XH}_{\mathrm{i}}$ highest composition processing limit for capture technology $\mathrm{j}(\mathrm{mol} \%)$

$\mathrm{XS}_{\mathrm{i}}$ carbon dioxide composition in the flue gas emission from source $\mathrm{i}(\mathrm{mol} \%)$

\section{Greek letters}

$\alpha_{\mathrm{I}, \mathrm{j}}$ parameter in capture and compression investment costs for technology $\mathrm{j}$

$\alpha_{o, j}$ parameter in capture and compression operating costs for technology $\mathrm{j}$

$\alpha_{t}$ parameter in transportation investment cost

$\beta_{\mathrm{I}, \mathrm{j}}$ parameter in in capture and compression investment costs for technology $\mathrm{j}$

$\beta_{o, j}$ parameter in capture and compression operating costs for technology $\mathrm{j}$

$\beta_{\mathrm{t}}$ parameter in transportation investment cost

$\gamma_{\mathrm{I}, \mathrm{j}}$ parameter in capture and compression investment costs for technology $\mathrm{j}$

$\gamma_{\mathrm{o}, \mathrm{j}}$ parameter in capture and compression operating costs for technology $\mathrm{j}$ 


\section{Appendix}

\section{Table 1}

Data cost for capture and compression technologies (Zhang et al., 2018; Nguyen and Zondervan, 2018)

\begin{tabular}{|c|c|c|c|c|c|c|}
\hline Process & Material & $\alpha$ & $\beta$ & $\gamma$ & $n$ & $m$ \\
\hline \multicolumn{7}{|c|}{ investment cost $(\$ / y)$} \\
\hline Absorption & MEA & 7719 & 67871 & 901.000 & 0.660 & 0.800 \\
\hline Absorption & PZ & 0 & 59956 & 226.932 & 0.566 & 0.800 \\
\hline PSA & $13 X$ & 220462 & 26720 & 895.262 & 0.508 & 0.804 \\
\hline PSA & AHT & 214535 & 17833 & 4607.297 & 0.744 & 0.813 \\
\hline PSA & MVY & 162447 & 22468 & 6408.791 & 1.000 & 0.797 \\
\hline PSA & WEI & 142320 & 19332 & 6076.357 & 0.610 & 0.779 \\
\hline VSA & $13 X$ & 91060 & 23096 & 7688.408 & 0.470 & 0.763 \\
\hline VSA & AHT & 113969 & 24939 & 2659.383 & 0.468 & 0.786 \\
\hline VSA & MVY & 119259 & 21652 & 8101.014 & 1.000 & 0.795 \\
\hline VSA & WEI & 180953 & 15644 & 7751.257 & 0.874 & 0.802 \\
\hline Membrane & $\begin{array}{l}\text { FSC } \\
\text { PVAm }\end{array}$ & 177500 & 16505 & 18912.000 & 0.880 & 0.770 \\
\hline Membrane & POE-1 & 568 & 19151 & 29669.274 & 0.778 & 0.735 \\
\hline Membrane & POE-2 & 53960 & 19967 & 28462.417 & 0.656 & 0.744 \\
\hline \multicolumn{7}{|c|}{ investment cost $(€ / y)$} \\
\hline \multicolumn{7}{|c|}{ operating cost $(\$ / y)$} \\
\hline Absorption & MEA & 0 & 24088 & 0 & 1.000 & 1.000 \\
\hline Absorption & PZ & 0 & 26825 & 0 & 0.945 & 0.966 \\
\hline PSA & $13 X$ & 0 & 11352 & 3115.833 & 1.000 & 0.974 \\
\hline PSA & AHT & 0 & 7040 & 983.893 & 0.626 & 1.000 \\
\hline PSA & MVY & 0 & 7265 & 1328.677 & 0.756 & 1.000 \\
\hline PSA & WEI & 0 & 6398 & 1257.721 & 0.554 & 0.991 \\
\hline VSA & $13 \mathrm{X}$ & 0 & 8167 & 1580.419 & 0.590 & 0.985 \\
\hline VSA & AHT & 0 & 8545 & 1725.654 & 0.842 & 0.996 \\
\hline VSA & MVY & 0 & 9117 & 1839.193 & 1.000 & 1.000 \\
\hline VSA & WEI & 0 & 7378 & 1493.500 & 0.753 & 1.000 \\
\hline Membrane & FSC & 0 & 11619 & 0 & 0.210 & 1.000 \\
\hline & PVAm & & & & & \\
\hline Membrane & POE-1 & 0 & 12798 & 0 & 0.134 & 0.980 \\
\hline Membrane & POE-2 & 0 & 13556 & 0 & 0.135 & 0.984 \\
\hline \multicolumn{7}{|c|}{ operating cost $(€ / y)$} \\
\hline Absorption & IL & 33172.59 & 897224.41 & 187421.22 & & 0.65 \\
\hline
\end{tabular}


Zhang, S., Zhuang, Y., Liu, L., Zhang, L., Du, J., 2019. Risk management optimization framework for the optimal deployment of carbon capture and storage system under uncertainty, Renewable and Sustainable Energy Reviews 113, 109280. https://doi.org/10.1016/j.rser.2019.109280

Nguyen, T.B.H., Zondervan, E. 2018. Ionic Liquid as a Selective Capture Method of CO2 from Different Sources: Comparison with MEA, ACS Sustainable Chemistry \& Engineering, 6 (4), 4845-4853.

10.1021/acssuschemeng. $7 \mathrm{~b} 04247$ 